\title{
Graphene-Based Nanomaterials Modulate Internal Biofilm Interactions and Microbial Diversity
}

\author{
Lauris Evariste $^{1 \star}$, Paul Braylé1, Florence Mouchet ${ }^{1}$, Jérôme Silvestre ${ }^{1}$, Laury Gauthier ${ }^{1}$, \\ Emmanuel Flahaut ${ }^{2}$, Eric Pinelli ${ }^{1}$ and Maialen Barret ${ }^{1}$
}

'Laboratoire d'écologie fonctionnelle et environnement, Université de Toulouse, CNRS, INPT, UPS, Toulouse, France, ${ }^{2}$ CIRIMAT, Université de Toulouse, CNRS, INPT, UPS, UMR CNRS-UPS-INP N05085, Université Toulouse 3 Paul Sabatier, Bât. CIRIMAT, Toulouse, France

Graphene-based nanomaterials (GBMs), such as graphene oxide (GO) and reduced graphene oxide ( $\mathrm{rGO}$ ), possess unique properties triggering high expectations for the development of new technological applications and are forecasted to be produced at industrial-scale. This raises the question of potential adverse outcomes on living organisms and especially toward microorganisms constituting the basis of the trophic chain in ecosystems. However, investigations on GBMs toxicity were performed on various

OPEN ACCESS

Edited by:

Soizic Morin,

INRAE Nouvelle-Aquitaine

Bordeaux, France

Reviewed by:

Mariana Carmen Chifiriuc, University of Bucharest, Romania Lingzhan Miao,

Hohai University, China

${ }^{*}$ Correspondence: Lauris Evariste lauris.evariste@gmail.com

Specialty section: This article was submitted to Microbiotechnology,

a section of the journal

Frontiers in Microbiology

Received: 30 October 2020 Accepted: 28 February 2021 Published: 26 March 2021

Citation:

Evariste L, Braylé P, Mouchet F, Silvestre J, Gauthier L, Flahaut E,

Pinelli E and Barret M (2021)

Graphene-Based Nanomaterials Modulate Internal Biofilm Interactions and Microbial Diversity.

Front. Microbiol. 12:623853.

doi: 10.3389/fmicb.2021.623853 microorganisms using single species that are helpful to determine toxicity mechanisms but fail to predict the consequences of the observed effects at a larger organization scale. Thus, this study focuses on the ecotoxicological assessment of GO and rGO toward a biofilm composed of the diatom Nitzschia palea associated to a bacterial consortium. After 48 and $144 \mathrm{~h}$ of exposure to these GBMs at 0, 0.1, 1, and $10 \mathrm{mg} \cdot \mathrm{L}^{-1}$, their effects on the diatom physiology, the structure, and the metabolism of bacterial communities were measured through the use of flow cytometry, $16 \mathrm{~S}$ amplicon sequencing, and Biolog ecoplates, respectively. The exposure to both of these GBMs stimulated the diatom growth. Besides, GO exerted strong bacterial growth inhibition as from $1 \mathrm{mg} \cdot \mathrm{L}^{-1}$, influenced the taxonomic composition of diatom-associated bacterial consortium, and increased transiently the bacterial activity related to carbon cycling, with weak toxicity toward the diatom. On the contrary, rGO was shown to exert a weaker toxicity toward the bacterial consortium, whereas it influenced more strongly the diatom physiology. When compared to the results from the literature using single species tests, our study suggests that diatoms benefited from diatom-bacteria interactions and that the biofilm was able to maintain or recover its carbon-related metabolic activities when exposed to GBMs.

Keywords: microbial ecotoxicology, graphene, freshwater, biofilm, diatom, metabarcoding

\section{INTRODUCTION}

Two-dimensional nanomaterials derived from graphene possess unique properties such as high surface area, electrical and thermal conductivity, mechanical strength, and optical transmittance that are currently being explored for the development of new applications in multiple area including composite improvement, energy storage, electronics, medicine, or water 
purification (Perreault et al., 2015; Dasari Shareena et al., 2018; Mohan et al., 2018; Nag et al., 2018). Among these graphenebased nanomaterials (GBMs), graphene oxide (GO), and reduced graphene oxide ( $\mathrm{rGO}$ ) appear as very attractive due to their ease of synthesis, their high stability after dispersion in various solvents and the possibility for surface functionalization (Smith et al., 2019). rGO, which carries a lower amount of oxygencontaining functions compared to GO (Lavin-Lopez et al., 2017), constitutes a good compromise between GO and graphene, especially for electrical conductivity properties, leading to its use for the development of electrochemical sensors (RowleyNeale et al., 2018; Tarcan et al., 2020). As the production of high quality graphene suffers from high energy consumption and cost, GO and rGO constitute major products in the graphene market (Lin et al., 2019). For these reasons, these GBMs are forecasted to be mass-produced and are thus likely to be released in the environment during their whole life cycle, from the production to the recycling (Mottier et al., 2017). However, the monitoring of environmental pollutions by GBMs is not possible yet due to technical limitations for their detection at current low concentrations in complex matrices (Goodwin et al., 2018). Nevertheless, despite the lack of modeling data about their expected environmental concentrations, it is estimated that with increasing needs, GBMs could reach concentrations between 1 and $1,000 \mu \mathrm{g} / \mathrm{L}$ in aqueous environment (Zhang et al., 2017), with an accumulation trend in sediment (Sun et al., 2016; Avant et al., 2019). This requires to carefully evaluate the potential impact of these materials on environmental health, in order to contribute to the development of this nanotechnology in a safety and sustainable way (Fadeel et al., 2018).

Previous studies investigated the toxicity of GBMs toward various aquatic organisms including vertebrates (Clemente et al., 2019; Evariste et al., 2019; Paital et al., 2019) or invertebrates (Castro et al., 2018; Lv et al., 2018), while the most abundant literature concerns the effects on bacteria and microalgae (Han et al., 2019; Kumar et al., 2019; Tashan et al., 2019; Saxena et al., 2020). Studying the effects of GBMs on these microorganisms is essential since they play crucial roles in aquatic ecosystems. Indeed, microalgae ensure primary production through photosynthesis while bacterial heterotrophic activities contribute to organic matter and nutrient cycling (Paerl and Pinckney, 1996; Scala and Bowler, 2001). Moreover, these microorganisms are at the basis of the trophic chain in the environment and act as a resource supplier for many primary consumers. Thus, impairment of these communities by GBMs exposure could indirectly affect organisms from higher trophic levels (Evariste et al., 2020). The vast majority of the studies available on bacteria and algae were performed on isolated single strains (e.g., Escherichia coli, Staphylococcus aureus, and Chlorella sp.) and highlighted antibacterial activities, and algal growth inhibitory effects of GBMs that were both associated to oxidative stress and membrane injuries (Ouyang et al., 2015; Ji et al., 2016; Zhao et al., 2017). Although these effects are well-documented in free-living cells, data concerning GBMs toxicity toward microorganisms living in complex biofilms remain scarce and inconsistent despite the fact that environmental biofilms are recognized to bind and accumulate nanoparticles (Ikuma et al., 2015). Biofilm lifestyle confers ecological advantages over free-living cells as it includes social cooperation as well as enhanced resource capture and resistance to antimicrobials for the organisms embedded in a matrix of extracellular polymeric substances (EPS; Flemming et al., 2016).

The main literature available focus on the effects of metallic nanoparticles toward biofilms, while studies focusing on carbonbased nanomaterials remains scarce (González et al., 2015; Lawrence et al., 2016; Hou et al., 2017; Miao et al., 2019). Specifically, the effects of GBMs toward biofilms were monitored on single bacterial strains in order for the development of antimicrobial treatments to avoid the formation of pathogenic biofilms for biomedical purposes (Han et al., 2019; Liu et al., 2019; Cacaci et al., 2020; Cao et al., 2021). In this context, studies indicated that GO-coated surfaces could either promote or inhibit biofilm formation by E. coli and S. aureus (Ruiz et al., 2011; Guo et al., 2017; Yadav et al., 2017). However, these studies were performed under conditions that are not fully relevant within environmental-based contexts that are not sufficiently investigated (Jastrzębska and Olszyna, 2015; Montagner et al., 2016). Thus, understanding the toxicological effects of GBMs toward more complex communities is crucial to better characterize the ecotoxic potential of these nanomaterials and to further determine the possible consequences of their presence in freshwater environments on the ecosystem functioning. The aim of this study was to investigate the toxicity of a commercial GO and its reduced form toward a complex assembly composed by the diatom Nitzschia palea associated to a bacterial consortium. This biofilm was exposed under controlled conditions to GBMs at concentrations ranging from 0.1 to $10 \mathrm{mg} \cdot \mathrm{L}^{-1}$ to determine the effects on diatom physiology using flow cytometry, as well as on bacterial community structure and activity using high throughput $16 \mathrm{~S}$ sequencing and community-level physiological profiles, respectively.

\section{MATERIALS AND METHODS}

\section{Graphene-Based Nanomaterials}

Graphene oxide was provided by Antolin Group and prepared by oxidizing Grupo Antolin Carbon Nanofibers (GANF ${ }^{\circledR}$; Grupo Antolín, Burgos, Spain) using the Hummer's method (Hummers and Offeman, 1958; Lobato et al., 2016). We thermally reduced it at $200^{\circ} \mathrm{C}$ in $\mathrm{H}_{2}$ atmosphere into $\mathrm{rGO}$, as previously described (Evariste et al., 2019). GBMs were stored as dry powder in the dark and dispersions were prepared extemporaneously in order to avoid any possible change of material characteristics. Full characterization of the tested materials was detailed in previous work (Evariste et al., 2019) and characterization data are summarized in Table $\mathbf{1}$.

\section{Complex Biofilm Model and Exposure Procedure}

The experimental model for complex biofilms was composed of an association between an axenic strain of N. palea CPCC-160 
TABLE 1 | Physico-chemical characteristics of graphene oxide (GO) and reduced graphene oxide ( $\mathrm{rGO}$ ) used in the study.

\begin{tabular}{lcc}
\hline & Graphene Oxide & $\begin{array}{c}\text { Reduced Graphene } \\
\text { Oxide }\end{array}$ \\
\hline Carbon content (at. \%) & $69.0 \pm 0.4$ & $83.8 \pm 0.5$ \\
Oxygen content (at. \%) & $31.0 \pm 0.4$ & $16.2 \pm 0.3$ \\
Csp2 graphene (at. \%) & 35.5 & 64.5 \\
C-OH/C_O-C (at. \%) & 24.7 & 7.8 \\
C=O (at. \%) & 2.5 & 5.8 \\
O=C-O (at. \%) & 5.3 & 1.3 \\
Sat. (at. \%) & 1.4 & 4.5 \\
Number of layers (HRTEM) & $1-5$ & $1-5$ \\
Lateral size (TEM; $\mu$ m) & $0.2-8$ & $0.2-8$ \\
Specific surface area (BET; & $228 \pm 7$ & $16 \pm 0.5$ \\
$m^{2}$.g-1) & & \\
\hline
\end{tabular}

TEM, transmission electron microscope; HRTEM, high resolution TEM; BET, BrunauerEmett-Teller; at. \%, atomic \%.

provided by the Canadian Phycological Culture Center (University of Waterloo, Waterloo, ON, Canada) and a bacterial consortium isolated from water filters of the freshwater Museum-Aquarium of Nancy (France). After sampling, the consortium was suspended in $50 \%$ glycerol and stored at $-80^{\circ} \mathrm{C}$ until use.

Before the beginning of the exposure to GBMs, microorganisms were sequentially introduced in culture Flasks (Falcon 355,001, $600 \mathrm{ml}-150 \mathrm{~cm}^{2}$ ) as follows. Nitzschia palea was cultured as previously described in a modified $\mathrm{CHU}$ no. 10 basic medium, called SPE medium (SPE; $6.4<\mathrm{pH}<6.6$; Garacci et al., 2017). Standard growth conditions consisted in an incubation at $22 \pm 1^{\circ} \mathrm{C}$ on a rotary shaker $(50 \mathrm{rpm})$ in a culture room. An illumination of $50 \mu \mathrm{mol} \mathrm{m} \mathrm{m}^{-2} \mathrm{~s}^{-1}$ with a day/ night period of $14 / 10 \mathrm{~h}$, respectively, was applied. Two days prior to exposure $\left(\mathrm{T}_{-48 \mathrm{~h}}\right)$, diatoms were transferred at a density of $5 \times 10^{4}$ cells $/ \mathrm{ml}$ in a flask containing $50 \mathrm{ml}$ of SPE medium. After $24 \mathrm{~h}$ of growth in standard conditions $\left(\mathrm{T}_{-24 \mathrm{~h}}\right)$, diatoms reached a concentration of $9 \times 10^{4}$ cells $/ \mathrm{ml}$. Glycerol was removed from the bacterial consortium after centrifugation and the consortium was suspended in $100 \mathrm{ml}$ of SPE medium. Thus, at $\mathrm{T}_{-24 \mathrm{~h}}$, flasks containing diatoms were inoculated with the bacterial consortium to reach the concentration of $3 \times 10^{4}$ bacterial cells $/ \mathrm{ml}$, leading to the ratio of 3 diatoms per bacterial cells in each flask. After $24 \mathrm{~h}$, flasks were contaminated with GBMs (T0). For this purpose, nanomaterials were dispersed in SPE medium through the use of an ultrasonic bath for $10 \mathrm{~min}$ and autoclaved. Dilutions of the GBMs stock dispersions were carried out under axenic conditions in order to avoid contamination. Intermediary dispersions were prepared at $0.2,2$ and $20 \mathrm{mg} . \mathrm{L}^{-1}$. A volume of $50 \mathrm{ml}$ of GBMs-contaminated SPE media was added in the flasks to reach a final concentration of $0.1,1$, or $10 \mathrm{mg} . \mathrm{L}^{-1}$ of GBMs while uncontaminated medium was added in the control groups (T0). Exposures were performed over $144 \mathrm{~h}$ under standard conditions as previously indicated.

Biofilm was sampled after 48 and $144 \mathrm{~h}$ of exposure with the different concentrations of GBMs $(n=3$ per time and GBM concentration). For each sampling, the biofilm was gently scrapped and flask content was homogenized and divided into two fractions of $50 \mathrm{ml}$. The first fraction was used for diatom and bacteria counts as well as analysis of the diatom physiological parameters using flow cytometry. In addition, this fraction was also used to perform community level physiological profiles (CLPP) analysis. The second $50 \mathrm{ml}$ fraction was filtrated at $0.45 \mu \mathrm{m}$ (Whatman ${ }^{\circledR}$ Nuclepore $^{\mathrm{TM}}$ ) to collect the whole microorganism community and investigate the microbial community structure. Filters were stored individually in sterile tubes at $-80^{\circ} \mathrm{C}$ prior to further processing.

\section{Flow Cytometry Analysis}

Flow cytometric (FCM) analysis of the diatom N. palea and bacterial counts were performed using a Beckman-Coulter Cytoflex flow cytometer equipped with a $488 \mathrm{~nm}$ laser and data were collected and analyzed using Cytexpert v. 2.2.0.97 software.

\section{Microorganisms Counts and Growth Rate Calculation}

For N. palea counts, unstained algae were gated based on their forward scatter parameters (FSC-A) and chlorophyll fluorescence $(690 / 50 \mathrm{~nm})$. Bacteria were accounted using SYTO9 dye (Invitrogen). Samples were incubated with $5 \mu \mathrm{M}$ of the probe for $15 \mathrm{~min}$ in the dark at room temperature. Bacteria were detected and enumerated based on the fluorescence emitted by SYTO9-positive events $(525 / 40 \mathrm{~nm})$ and side scatter parameters (SSC-H). Normalized growth rates of the diatoms and bacteria were calculated as follows:

$$
\begin{aligned}
& \text { Growth rate }=\left(\frac{C s-\text { Mic }}{\text { Mic }}\right) \\
& \text { Normalized growth rate }(\%)=\left(\frac{\text { Growth rate }}{M C t G r}\right) \times 100
\end{aligned}
$$

Cs corresponds to the organism concentration at sampling time, Mic is the mean initial concentration of organisms (at $\mathrm{T}_{-48 \mathrm{~h}}$ for diatoms and at $\mathrm{T}_{-24 \mathrm{~h}}$ for bacteria) and MCtGr is the mean growth rate in the control group at sampling time.

\section{Diatom Physiological Parameters}

The relative chlorophyll a content of $N$. palea was determined through the measurement of natural chlorophyll a fluorescence emitted at 690/50 $\mathrm{nm}$. The mean fluorescence intensity (MFI in arbitrary unit) collected is expressed as a percentage of the negative control.

Diatom viability was evaluated using SYTOX ${ }^{\circledR}$ Green. After incubation with the probe for $10 \mathrm{~min}$ at a final concentration of $0.5 \mu \mathrm{M}$, cell suspensions were analyzed by flow cytometry to measure the fluorescence emitted at 525/40 nm. Diatoms with injured or permeable membrane are positive to the green fluorescence-emitting probe bound to DNA. Results are expressed as viability percentage (100\% - percentage of SYTOX-positive cells).

Neutral lipid relative content of the diatoms was evaluated using BODIPY (4,4-difluoro-1,3,5,7,-tetramethyl-4-bora-3a,4adiaza-s-indacene; 505/515). Algae were incubated for $1.5 \mathrm{~min}$ with the lipophilic dye at a final concentration of $1 \mu \mathrm{g} \cdot \mathrm{ml}^{-1}$ 
before FCM. The BODIPY fluorescence emitted by the stained diatoms was collected using a 530/30 nm band-pass filter. The MFI measured is presented as a percentage of the negative control.

The intracellular reactive oxygen species (ROS) produced by the diatoms was measured using $2^{\prime}, 7^{\prime}$-dicholorofluorescindiacetate (DCFH-DA), a marker of oxidative stress. Samples were stained for $30 \mathrm{~min}$ with the probe at a final concentration of $10 \mu \mathrm{M}$ prior running flow cytometry measurements. Diatoms with elevated intracellular ROS are positively stained by the probe (Thamatrakoln et al., 2012). The results are presented as a percentage of the diatom population emitting probe-related fluorescence.

\section{Analysis of Community Level Physiological Profiles}

BIOLOG $^{\circledast}$ EcoPlates, consisting of 96-well plates containing a triplicate of 31 different carbon sources and a control with no carbon source, were used to analyze the CLPP of the microorganism communities. Samples were diluted 100 times with fresh SPE medium and $120 \mu \mathrm{l}$ of the diluted suspension was transferred into each well of the plate. After inoculation, EcoPlates were incubated in aerobic conditions at $22 \pm 1^{\circ} \mathrm{C}$ in darkness for $144 \mathrm{~h}$. Optical density (OD) at $590 \mathrm{~nm}$ was measured immediately after microorganism plating $\left(\mathrm{T}_{\text {in }}\right)$ and was monitored daily over the $144 \mathrm{~h}$ with a CLARIOStar plate reader (BMG Labtech). Over these $144 \mathrm{~h}$, OD increased linearly $\left(r^{2}=0.94\right)$ and did not reached a plateau phase. For each substrate, absorbance was corrected by subtracting the absorbance of the control well containing media only. Negative values of the corrected readings were set to zero. The average well color development (AWCD) of substrate utilization was calculated across all wells per plate as follows:

$$
A W C D=\left(\sum O D i\right) / 31,
$$

where $O D i$ represent the corrected optical density of the ith well. AWCD was also calculated for each guild of carbon sources, grouped into (1) carbohydrates, (2) carboxylic acids, (3) amino acids, (4) amines and amides, and (5) polymers as defined by Weber and Legge (2009). To compensate the influence of the microorganism density on the AWCD measurement, corrected OD values were calculated per bacteria by dividing the OD value per the number of bacteria introduced in each well at $\mathrm{T}_{\text {in }}$. The normalized carbon source utilization data were also subjected to principal components analysis (PCA). All the results reported refer to the $144 \mathrm{~h}$ time point.

\section{Analysis of Bacterial Community Structure: DNA Extraction, PCR, Sequencing, and Data Processing}

After cutting filters into pieces, total DNA was extracted using the QIAGEN DNeasy PowerSoil kit following manufacturer's instructions. Extraction controls were performed using unused filters to ensure the absence of DNA contamination. The DNA extracts quantity and quality were analyzed using a NanoDrop 2000 UV spectrophotometer (Thermo Scientific). The V4-V5 region of 16S rRNA gene was targeted for Archaea and Bacteria using 515F (5'-GTGYAGCMGCCGCGGTA-3') and 928R (5'-CCCCGYCAATTCMTTTRAGT-3') primers set (Wang and Qian, 2009). PCR reactions were run in a final volume of $50 \mu \mathrm{l}$ containing: $37.5 \mu \mathrm{l}$ of PCR water, $5 \mu \mathrm{l}$ of 10X PCR buffer, $2 \mu \mathrm{l}$ of DNA extract, $2 \mu \mathrm{l}$ of both primer, $1 \mu \mathrm{l}$ of dNTP $(2.5 \mathrm{mM})$ and $0.5 \mu \mathrm{l}$ of Taq DNA polymerase (5 U/pl - Sigma Aldrich). The following PCR protocol was applied: $94^{\circ} \mathrm{C}$ for $120 \mathrm{~s}, 30$ cycles of $94^{\circ} \mathrm{C}$ for $60 \mathrm{~s}, 65^{\circ} \mathrm{C}$ for $40 \mathrm{~s}, 72^{\circ} \mathrm{C} 30 \mathrm{~s}$, and $72^{\circ} \mathrm{C}$ for $10 \mathrm{~min}$. Sequencing of the resulting amplicons was performed using Illumina MiSeq technology $(2 \times 250 \mathrm{pb})$ by the Get_PlaGe platform (Genotoul, Toulouse, France). Bioinformatic analysis was performed using Find Rapidly Operational Taxonomic Units Galaxy Solution (FROGS) pipeline on Galaxy (Escudié et al., 2018). Briefly, sequences with mismatch in the primers were excluded and PCR primers were trimmed. Reads were clustered into operational taxonomic units (OTUs) using the Swarm clustering method (Mahé et al., 2014). Chimera was removed and filters were applied to remove singletons and keep OTUs present in at least two samples. OTUs were assigned at different taxonomic levels (from Kingdom to species) using RDP classifier and NCBI Blast+ against Silva 138 database (pintail 80; Quast et al., 2012). Amplicons affiliated to the diatom chloroplast and mitochondria were removed from the dataset prior to data analysis.

\section{Statistical Analysis}

As interactive effects were observed between the exposure duration and the contaminant concentrations using two-ways ANOVA, one-way ANOVA was performed at each sampling time to compare the effects induced by the different concentrations of contaminant. Thus, data related to microorganism growth rates, diatom physiological parameters, and community physiological profiles were analyzed using one-way ANOVA when assumptions of normality and homogeneity of variance were met. Otherwise, data were transformed to meet these assumptions and data were analyzed using Minitab 16 Statistical software. Concentrations leading to $50 \%$ of bacterial growth inhibition $\left(\mathrm{IC}_{50}\right)$ were determined using non-linear Hill regression in Graphpad Prism software.

Sequencing data analyses for OTUs counts, alpha diversity indexes, and Weighted Unifrac Distances calculations as well as multidimensional scaling (MDS) plot were carried out using the R package "Phyloseq" (McMurdie and Holmes, 2013). Differential abundance of bacterial genera between exposed conditions compared to the control group was examined using "Deseq2" R package (Love et al., 2014). PERMANOVA was performed using Adonis function from the "vegan" $\mathrm{R}$ package (Oksanen et al., 2015).

\section{RESULTS}

\section{Effects on Microorganism Growth Rates}

Exposure to the GBMs led to a transitory growth stimulation of the diatom. At $\mathrm{T}_{48 \mathrm{~h}}$, the growth rate calculated in the control 
group reached a value of $5.4 \pm 0.95$ (Supplementary Figure S1). Except after exposure to $\mathrm{GO}$ at $0.1 \mathrm{mg} . \mathrm{L}^{-1}$, a significant growth stimulation was observed in all GBMs-containing conditions (ANOVA $p<0.001$ ), reaching $268 \pm 31 \%$ of the control group value after exposure to $10 \mathrm{mg} . \mathrm{L}^{-1}$ of rGO (Figure 1A). After $144 \mathrm{~h}$ of exposure, none of the growth rates calculated in the exposure conditions were significantly different from the control group (Figure 1B). In addition, growth rates of the diatom calculated after $48 \mathrm{~h}$ of exposure to GBMs reached values similar to the control group at $\mathrm{T}_{144 \mathrm{~h}}(12.7 \pm 2.6$; $t$-test; $p=0.604$; Supplementary Figure S1).

For the bacterial compartment, exposure to GO led to a dose dependant growth inhibition from $1 \mathrm{mg} . \mathrm{L}^{-1}$, while only a slight inhibition was noticed after exposure to $\mathrm{rGO}$ at $10 \mathrm{mg} . \mathrm{L}^{-1}$ (Figure 1C). The calculated concentrations leading to a growth inhibition of $50 \%\left(\mathrm{IC}_{50}\right)$ were $2.18 \mathrm{mg} . \mathrm{L}^{-1}$ and 13.25 mg. $\mathrm{L}^{-1}$ after 48 and $144 \mathrm{~h}$ of exposure to GO, respectively. Contrary to the recovery observed for diatoms at $144 \mathrm{~h}$, bacterial growth rates were still significantly different from the control at 1 and $10 \mathrm{mg} \cdot \mathrm{L}^{-1}$ of $\mathrm{GO}$ to at $10 \mathrm{mg} \cdot \mathrm{L}^{-1}$ of rGO (Figure 1D).

\section{Effects on N. palea Physiology}

The relative chlorophyll content of the diatom remained unchanged after $48 \mathrm{~h}$ of exposure to the GBMs (Figure 2A) while a higher relative chlorophyll content could be measured in the diatoms exposed to GO at $10 \mathrm{mg} . \mathrm{L}^{-1}$ during $144 \mathrm{~h}$ (Figure 2B). On the contrary, exposure to rGO led to a slight decrease of the chlorophyll content after $144 \mathrm{~h}$ of contact with rGO (Figure 2B).

Graphene oxide exposure did not lead to any significant change in the lipid content of the diatom while in rGO containing conditions, an accumulation of lipids was measured, with a more marked effect after $48 \mathrm{~h}$ of exposure (Figures 2C,D).

Measurement of oxidative stress in the diatom indicated a significant oxidative stress after $48 \mathrm{~h}$ of exposure to $\mathrm{rGO}$ at $10 \mathrm{mg} . \mathrm{L}^{-1}$ (Figure 2E) while no DCF-positive cells were observed at $\mathrm{T}_{144 \mathrm{~h}}$ (data not shown). Monitoring of the diatom viability highlighted a significantly higher percentage of alive diatoms after $48 \mathrm{~h}$ of exposure to GO at 1 and $10 \mathrm{mg} \cdot \mathrm{L}^{-1}$ (ANOVA, $p=0.027$, Figure $2 \mathrm{~F})$. At $\mathrm{T}_{144 \mathrm{~h}}$, no differences were observed between the different GBMs-containing conditions and the control group in the diatom viability that reached that $99 \pm 0.64 \%$ (data not shown).

\section{Effects of GBMs Exposure on Community Level Physiological Profiles}

The community level physiological profile of the biofilm was monitored using Biolog ${ }^{\circledR}$ Ecoplate after 48 and $144 \mathrm{~h}$

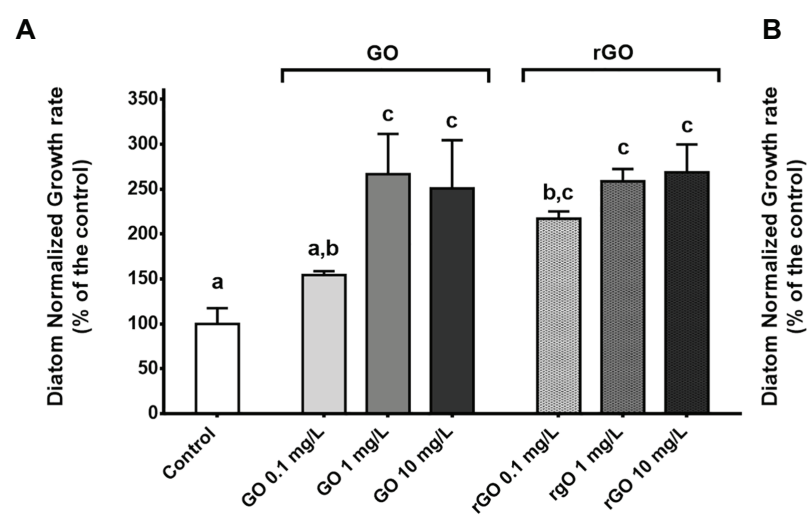

C

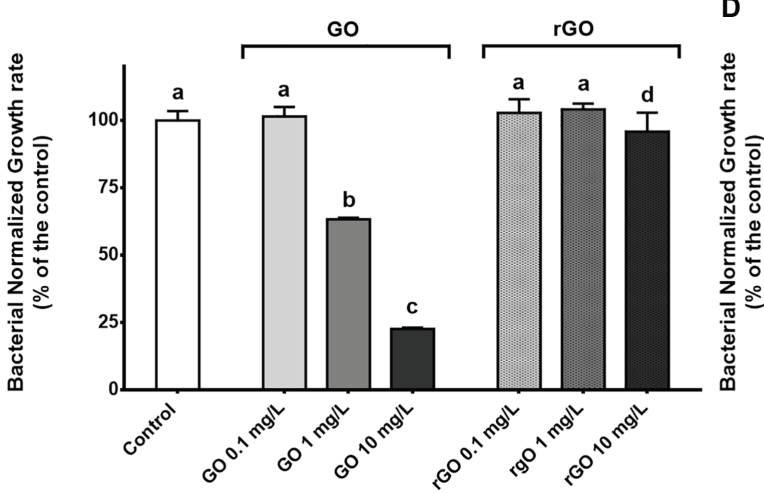

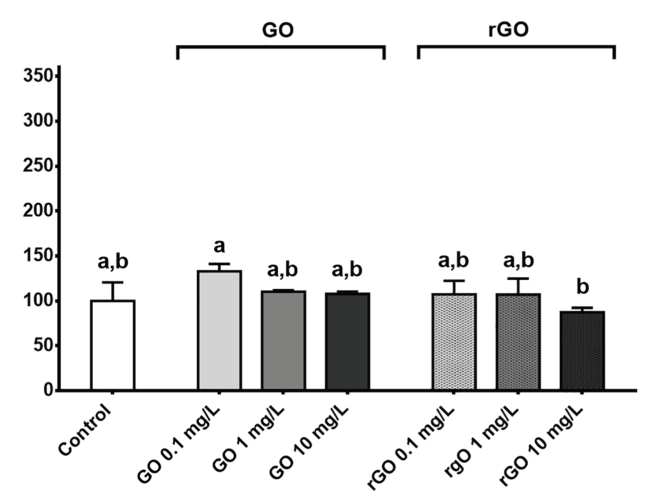

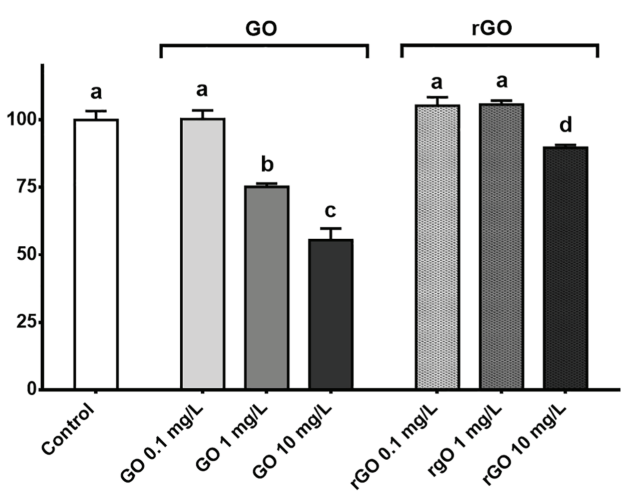

FIGURE 1 | Normalized growth rate of the diatom Nitzschia palea calculated after $48 \mathrm{~h}$ (A) and $144 \mathrm{~h}$ (B) of exposure to graphene-based nanomaterials (GBMs). Normalized growth rate of the bacterial consortium calculated after $48 \mathrm{~h}$ (C) and $144 \mathrm{~h}$ (D) of exposure to GBMs. ANOVA was followed by Tukey test. Letters indicate significant differences between the tested conditions. 


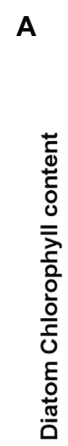
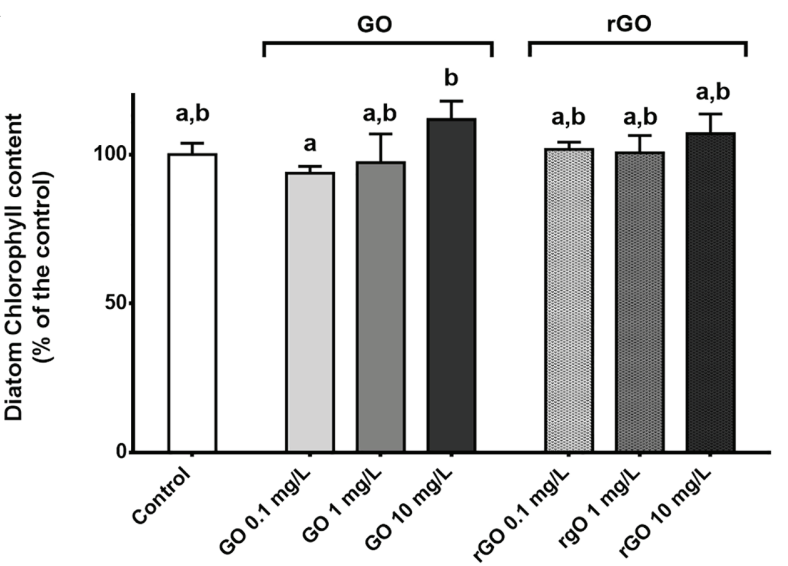

C

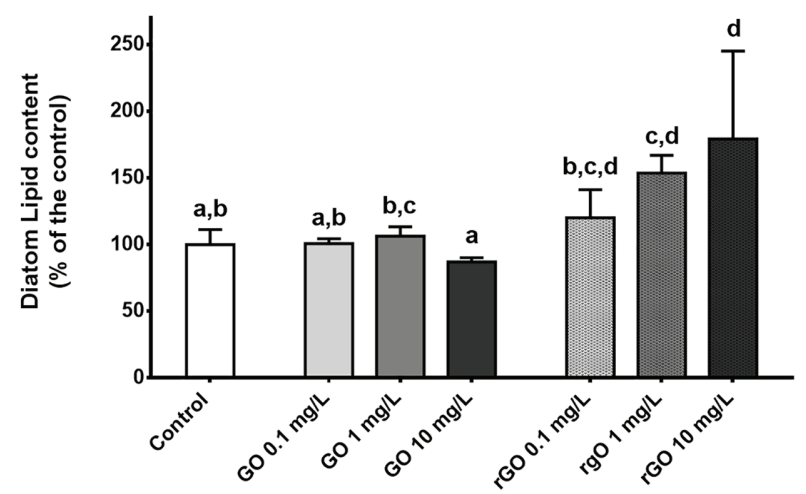

E

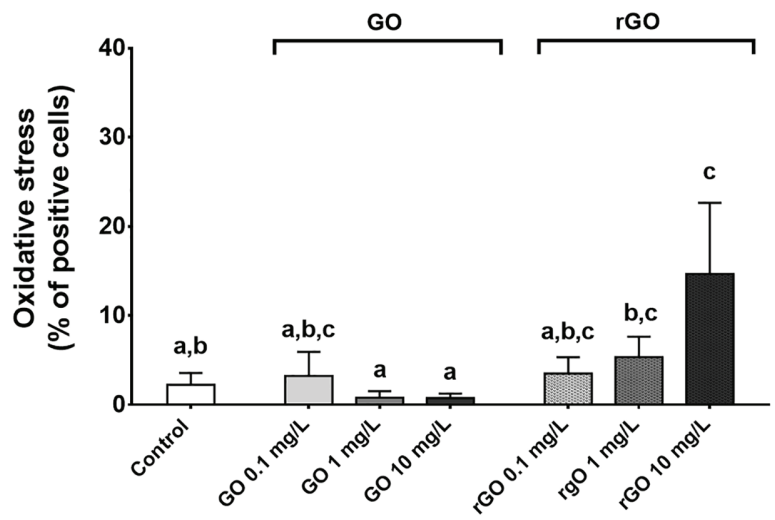

B
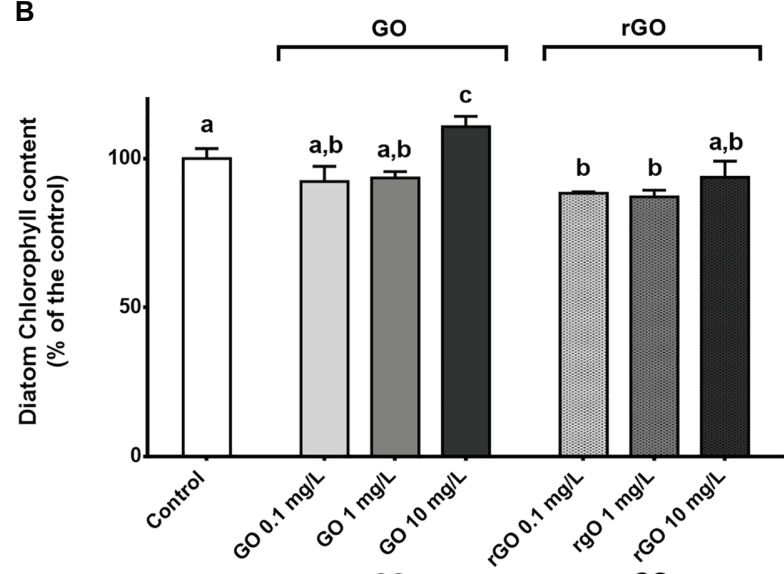

D

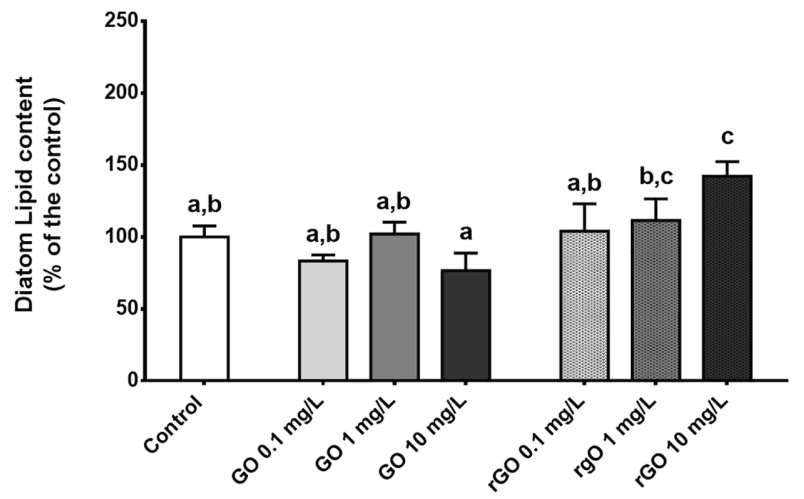

$\mathbf{F}$

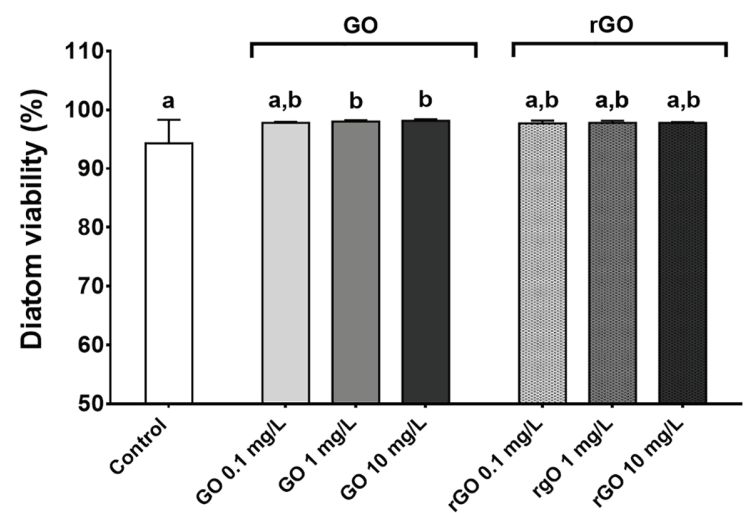

FIGURE 2 | Physiological parameters of the diatom N. palea following exposure to GBMs. Normalized chlorophyll content measured after $48 \mathrm{~h}$ (A) and $144 \mathrm{~h}$ of exposure (B), normalized lipid content measured after $48 \mathrm{~h}$ (C) and $144 \mathrm{~h}$ (D), oxidative stress (E) and viability (F) following $48 \mathrm{~h}$ of exposure to GBMs. Values are presented as mean \pm SD. ANOVA $(p<0.05)$ was followed by Tukey test. Letters indicate significant differences between the tested conditions.

of exposure to the different concentrations of GBMs. As indicated by the normalized AWCD values as well as the PCA results, a dose-dependent increase of the overall utilization of carbon sources was noticed after $48 \mathrm{~h}$ of exposure to GO while the substrate utilization did not differ from the control group after exposure to rGO (Figure 3A; Supplementary Figures S2A,B). In the case of GO exposure, this increase of normalized AWCD values resulted from an increase of the utilization of all the different guilds of carbon sources (Supplementary Figure S3A). At $\mathrm{T}_{144 \mathrm{~h}}$, the normalized AWCD values were significantly lower in the control group compared to $\mathrm{T}_{48 \mathrm{~h}}$ ( $t$-test, $p=0.016$ ) and values were not significantly different from the control group after exposure to GBMs (Figure 3B). However, according to PCA results, carbon sources utilization appears to be different from the control in every GO-containing condition 

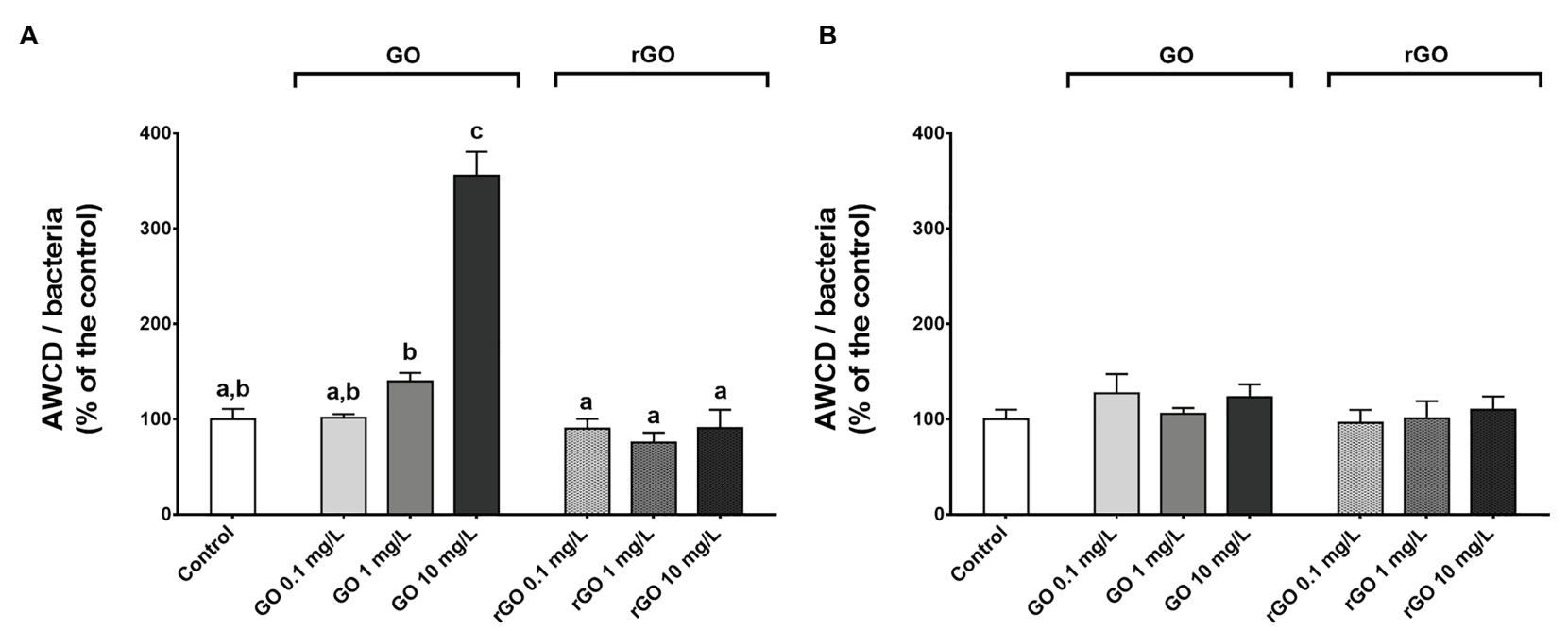

FIGURE 3 | Normalized average well color development (AWCD) values measured after 48 h (A) and 144 h (B) of exposure to GBMs. ANOVA followed by Tukey test. Letters indicate significant differences between the tested conditions.

(Supplementary Figure S2C). This is associated to an increased utilization of the polymers guild (Supplementary Figure S3B). Similarly, PCA results suggest changes in the CLPP after $144 \mathrm{~h}$ of exposure to $\mathrm{rGO}$ at $10 \mathrm{mg} \cdot \mathrm{L}^{-1}$ compared to unexposed biofilm (Supplementary Figure S2D). In this condition, carbon sources 4-hydroxy benzoic acid, itaconic acid, and $\mathrm{D}$-xylose appeared to be utilized by the microbial consortium while it was not the case in other conditions. The highest average AWCD values measured in the control group at both 48 and $144 \mathrm{~h}$ was for the carbohydrate and amino acid guilds while after $144 \mathrm{~h}$ of exposure to GO at 1 and $10 \mathrm{mg} . \mathrm{L}^{-1}$, the utilization of the substrates from the polymers guild is favored.

\section{Effects on Bacterial Community Structure}

After $48 \mathrm{~h}$ of exposure, the Shannon indexes calculated for the bacterial communities were similar in the GBMs containing conditions compared to the control group (ANOVA $p=0.305$; Figure 4A) and the bacterial community structure was not significantly affected as revealed by MDS and PERMANOVA analysis using weighted UniFrac distances (PERMANOVA, $p=0.221$; Figure 4B). Between 48 and $144 \mathrm{~h}$, the trajectory of bacterial communities in control conditions resulted in a decrease of Shannon index (Figure 4B). However, after $144 \mathrm{~h}$ of exposure to GO at $10 \mathrm{mg} \cdot \mathrm{L}^{-1}$, the Shannon index was significantly higher than in the control (ANOVA, $p<0.001$; Figure 4C) when compared to the control group. At $\mathrm{T}_{144 \mathrm{~h}}$, the exposure to GBMs significantly affected the bacterial community structure (PERMANOVA: $p=0.001$ ) and MDS analysis revealed that the effects were more marked after exposure to GO at 10 mg. $\mathrm{L}^{-1}$ (Figure 4D).

At $\mathrm{T}_{48 \mathrm{~h}}$ in the control group, over $98 \%$ of the bacteria constituting the biofilm belonged to the phyla Proteobacteria and Bacteroidota, accounting for $60.7 \pm 2.0 \%$ and $38 \pm 1.5 \%$ of the total bacteria, respectively (Figure 5). At $\mathrm{T}_{144 \mathrm{~h}}$, these two phyla represented over $99 \%$ of the whole community but the relative abundance of the phylum Proteobacteria decreased to $37.0 \pm 4.9 \%$ while it increased to $62.5 \pm 4.7 \%$ for the phylum Bacteroidota (Figure 5). At $\mathrm{T}_{48 \mathrm{~h}}$, the relative abundances of these two phyla were not affected by the GBMs exposure (Bacteroidota: ANOVA, $p=0.954$; Proteobacteria: ANOVA, $p=0.944)$. After $144 \mathrm{~h}$ of exposure to the different concentrations of GBMs, only the exposure to $\mathrm{GO}$ at $10 \mathrm{mg} . \mathrm{L}^{-1}$ led to significant changes in the phyla distribution. In this condition, the relative abundance of the phylum Bacteroidota was significantly lower $(51.8 \pm 3.5 \%)$ compared to the one observed in the control group (ANOVA, $p=0.001$ followed by Tuckey test), while the relative abundance of the phylum Proteobacteria was significantly higher (47.8 $\pm 3.4 \%$; ANOVA, $p=0.002$ followed by Tuckey test).

At $\mathrm{T}_{48 \mathrm{~h}}$, OTUs assigned to the phylum Bacteroidota were mainly members of the orders Chitinophagales and Sphingobacteriales (Supplementary Figure S4A). Members from the order Burkholderiales and Rhodobacterales predominated among OTUs affiliated to the phylum Proteobacteria (Supplementary Figure S4B). While Burkholderiales and Rhodobacterales members still predominated over other Proteobacteria after $144 \mathrm{~h}$ of incubation, the relative abundance of OTUs affiliated to the Order Xanthomonadales increased over time in all conditions (Supplementary Figure S4B). Statistical analysis of the OTUs relative abundances in the biofilm indicated that four OTUs from the phylum Proteobacteria were differentially abundant upon exposure to GBMs, with a significance threshold fixed at $p=0.01$. All four OTUs were more abundant after exposure to $10 \mathrm{mg} . \mathrm{L}^{-1}$ of $\mathrm{GO}$ during $144 \mathrm{~h}$ than in control condition. Two of these OTUs, with a $\log 2$-fold change of $6.79 \pm 1.2$ and $5.82 \pm 1.1$, were affiliated to the genus Acidovorax while the two others with a $\log 2$-fold 
A

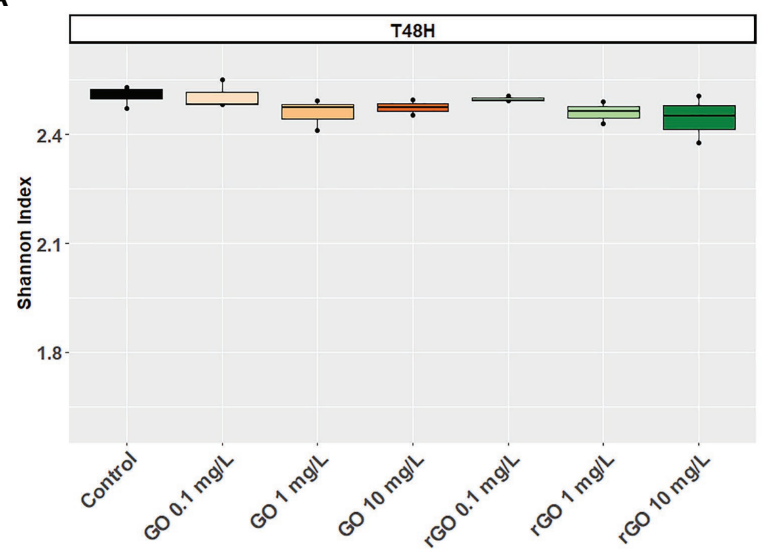

B

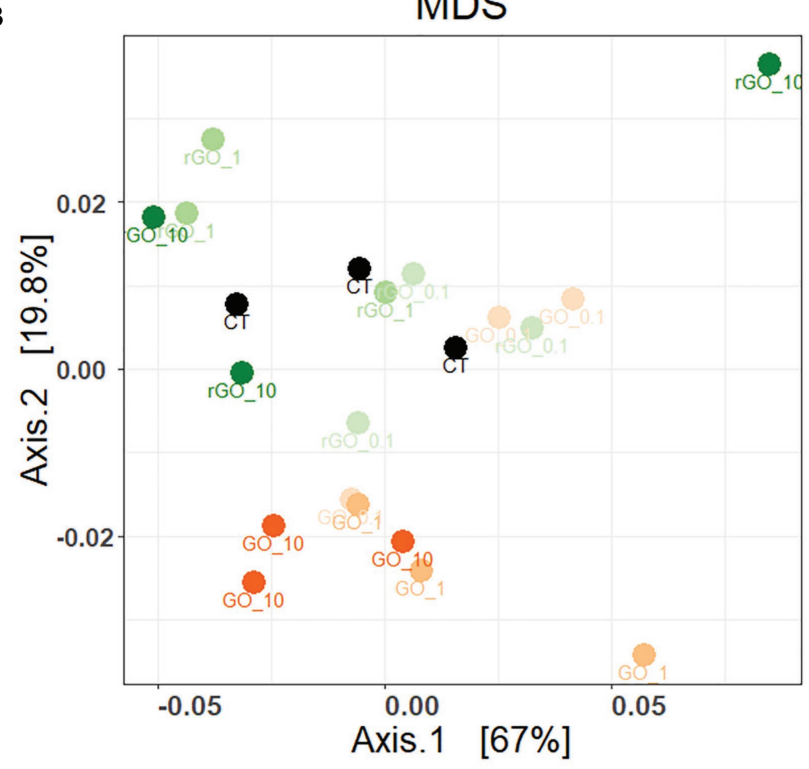

C

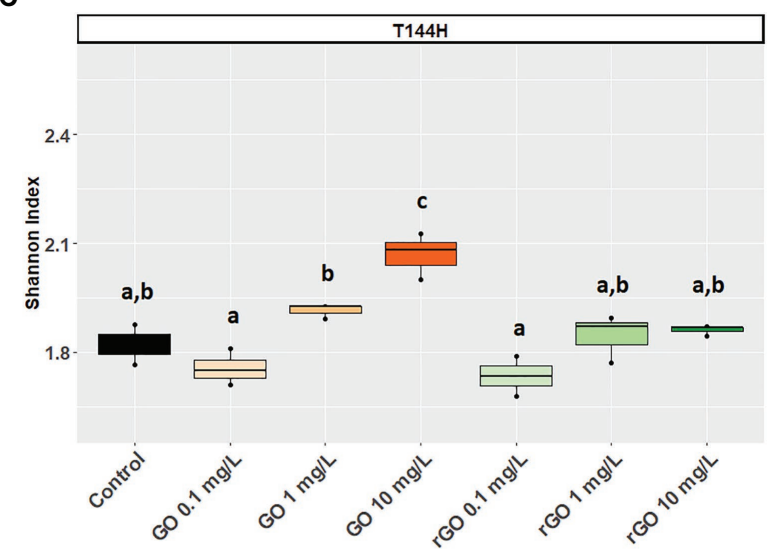

D

MDS

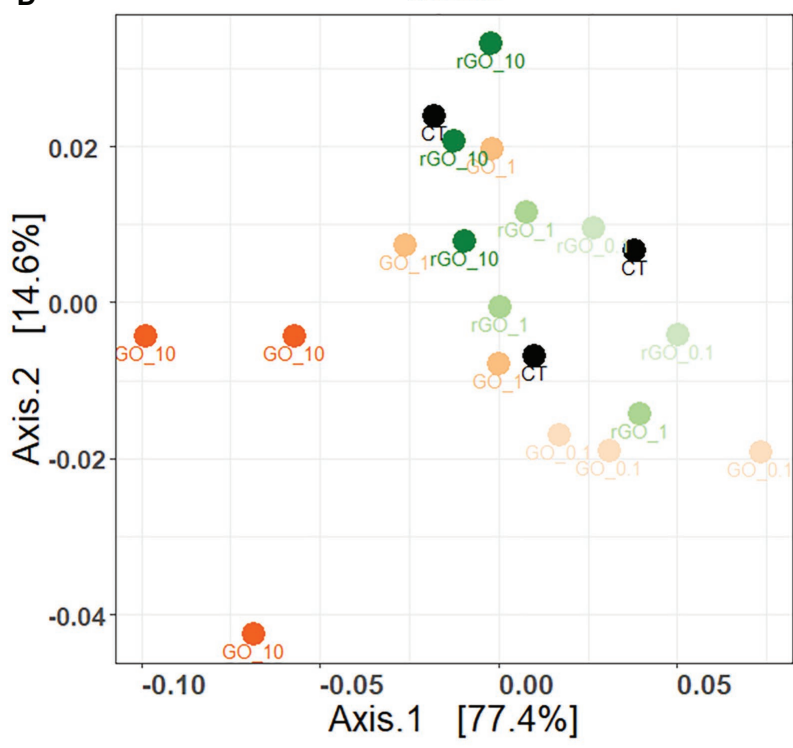

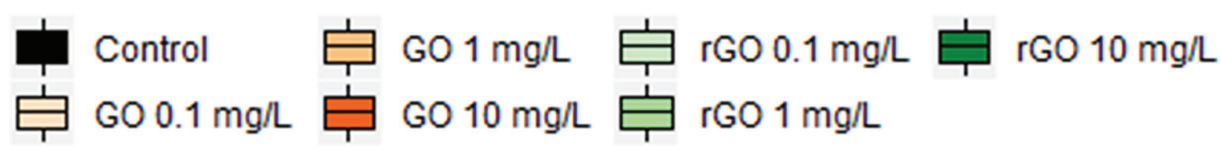

FIGURE 4 | Effects of exposure to GBMs on bacterial communities from the biofilm. Shannon evenness index following $48 \mathrm{~h}$ (A) or $144 \mathrm{~h}$ of exposure to GBMs (C) are compared between the exposure conditions. ANOVA followed by Tukey test. Letters indicate significant differences between the tested conditions. Multidimensional scaling (MDS) plot of bacterial communities based on unweighted Unifrac distances after $48 \mathrm{~h}$ (B) and $144 \mathrm{~h}$ (D) of exposure to the different conditions.

change of $1.81 \pm 0.4$ and $1.95 \pm 0.2$ belonged to the genus Silanimonas (Table 2). In the control group, the relative abundance of the two Acidovorax members (OTUs 29 and 18) decreased between $\mathrm{T}_{48 \mathrm{~h}}$ and $\mathrm{T}_{144 \mathrm{~h}}$ while it increased for the two Silanimonas sp. (OTUs 9 and 61; Figure 6). Upon exposure to GO at $10 \mathrm{mg} \cdot \mathrm{L}^{-1}$, these OTUs followed different trajectories compared to the control conditions. Thus, the increases of the former OTUs were enhanced while the decreases were less marked over time for the latter OTUs (Figure 6). For example, the OTU 9 increased from $0.18 \pm 0.02 \%$ at $\mathrm{T}_{48 \mathrm{~h}}$ to $1.7 \pm 0.2 \%$ at
$\mathrm{T}_{144 \mathrm{~h}}$ in the control group whereas it reached $6.2 \pm 1.2 \%$ following exposure to $\mathrm{GO}$ at $10 \mathrm{mg} \cdot \mathrm{L}^{-1}$.

\section{DISCUSSION}

Due to the multiple crucial roles played by microbial communities in the environment, studying the effects of GBMs toward these communities is essential to better assess the ecosystemic consequences of a contamination of the environment by these 


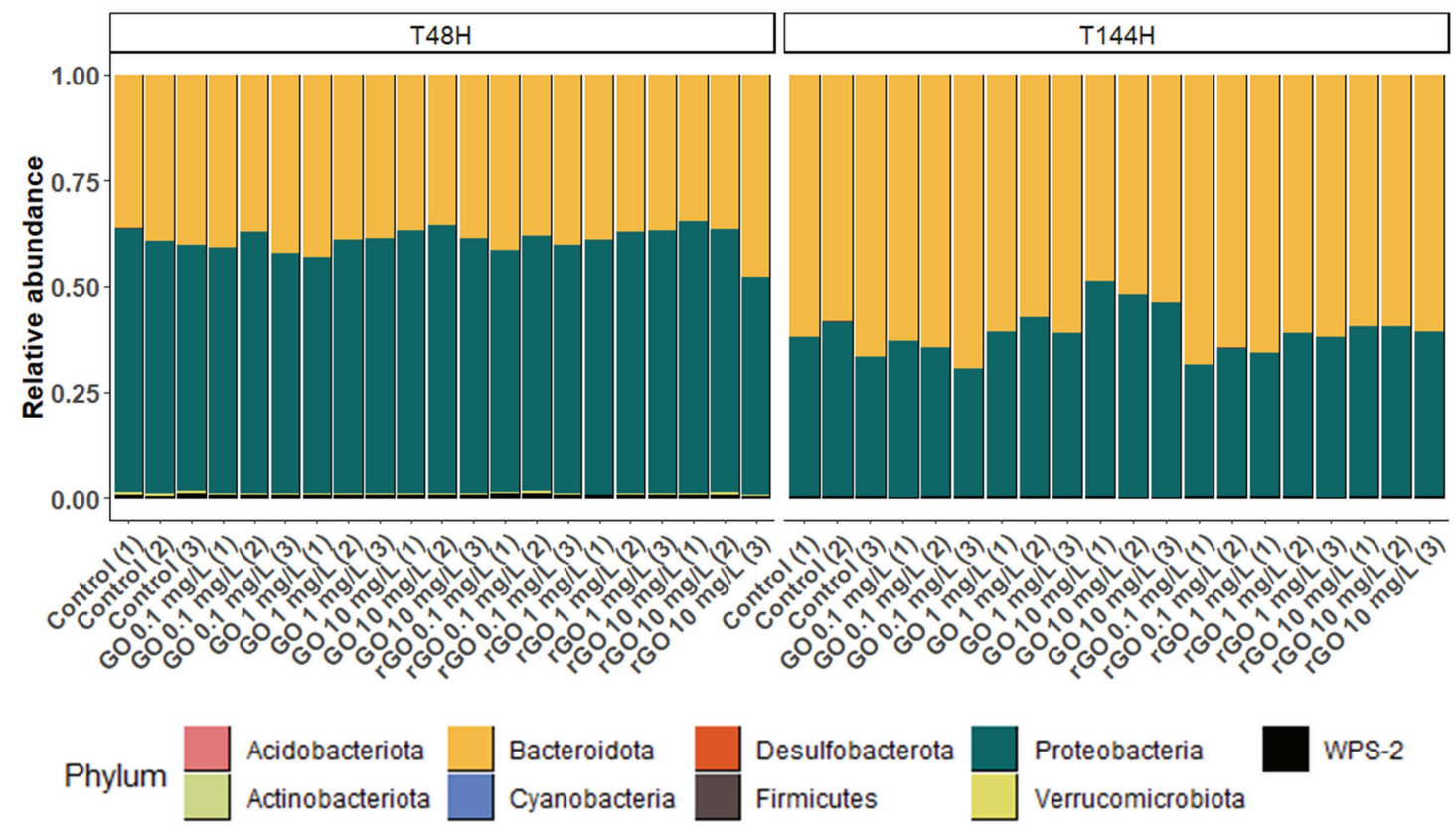

FIGURE 5 | Relative abundance of bacterial phyla from the biofilm after $48 \mathrm{~h}\left(\mathrm{~T}_{48 \mathrm{~h}}\right)$ and $144 \mathrm{~h}\left(\mathrm{~T}_{144 \mathrm{~h}}\right)$ of exposure to $\mathrm{GO}$ or rGO at concentrations ranging from 0 to $10 \mathrm{mg} \cdot \mathrm{L}^{-1}$.

TABLE 2 | Operational taxonomic units (OTUs) differentially abundant $(\mathrm{p}<0.01)$ at $10 \mathrm{mg} \cdot \mathrm{L}^{-1}$ of GO compared to the control group after $144 \mathrm{~h}$ of exposure.

\begin{tabular}{lclllll}
\hline OTU & Log2-fold change & Phylum & Class & Order & Family & Genus \\
\hline 18 & 6.79 & Proteobacteria & Gammaproteobacteria & Burkholderiales & Comamonadaceae & Acidovorax \\
29 & 5.82 & Proteobacteria & Gammaproteobacteria & Burkholderiales & Comamonadaceae & Acidovorax \\
61 & 1.81 & Proteobacteria & Gammaproteobacteria & Xanthomonadales & Xanthomonadaceae & Silanimonas \\
9 & 1.95 & Proteobacteria & Gammaproteobacteria & Xanthomonadales & Xanthomonadaceae & Silanimonas \\
\hline
\end{tabular}

Positive log2-fold change values indicate enriched OTUs in the exposure condition.
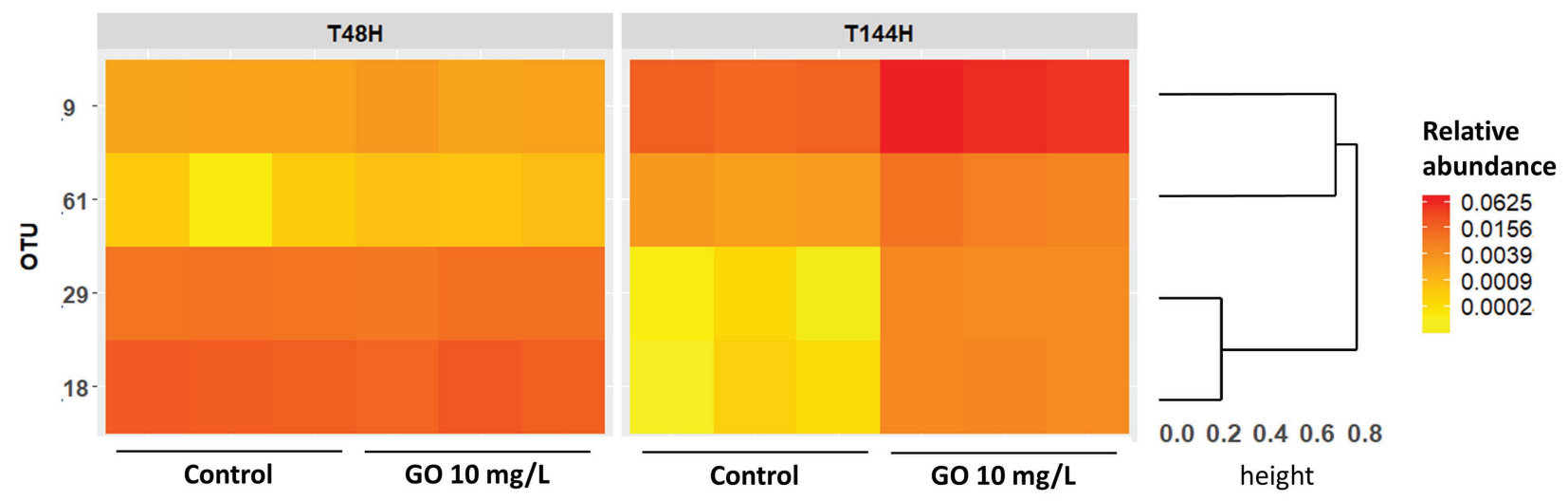

FIGURE 6 | Heatmap showing the relative abundances of the discriminant OTUs identified by Deseq analysis. The dendrogram is based on Bray-Curtis distances metric and hierarchical clustering of OTUs using the complete method.

nanomaterials. For this purpose, many studies evaluated their ecotoxic potential through the use of single-species-based assays. These tests are relevant to determine the toxicological effects and pathways associated to GBMs exposure but they are not realistic and fail to inform the consequences that could occur when interacting species are exposed. As litterature about GBMs 
impact on complex communities is scarce for the aquatic environment, this study aims to fill the gap on the subject.

\section{Consequences of the GBMs Exposure on the Algal Compartment}

In our study, exposure to the different GBMs concentrations led to a growth stimulation of the diatom $N$. palea, reaching the maximum growth rate earlier compared to the control group, the growth rate of the latter being comparable to previous studies (Garacci et al., 2017). These results are contradictory with the vast majority of single-species-based studies which indicated that exposure to engineered nanoparticles led to algal growth inhibition associated to oxidative stress induced by cellular damages (Chen et al., 2019; Saxena et al., 2020). For example, this was observed for green pelagic algae such as Raphidocelis subcapitata, Chlorella pyrenoidosa, or Scenedesmus obliquus after exposure to GO or rGO (Du et al., 2016; Zhao et al., 2017, 2019; Malina et al., 2019). It was also indicated that the exposure of the freshwater diatom $N$. palea to few layer graphene (FLG) increased the production of EPS substances which mitigated its toxicity (Garacci et al., 2017, 2019). Despite the difference of sensitivity of the different algal species to GBMs, the concentrations leading to $50 \%$ of algal growth inhibitions all ranged from 20 to over $150 \mathrm{mg} . \mathrm{L}^{-1}$, which is approximately one order of magnitude higher than the concentrations tested in our study (Nogueira et al., 2015; Du et al., 2016; Zhao et al., 2017). In our work, the similar trends observed on the increase of the diatom growth following exposure to $\mathrm{GO}$ or $\mathrm{rGO}$ suggest that this response may not be influenced by specific physico-chemical characteristics such as oxidation level. In addition, the weak oxidative stress measured in the diatom is consistent with the absence of growth impairment and highlights the protective effect associated to the biofilm lifestyle. Growth inhibitory effects were also hypothesized to be associated to indirect ecotoxic effects through shading as well as to nutrient depletion by GBMs (Garacci et al., 2017; Zhao et al., 2017). As the algal growth increased, these two hypotheses are unlikely under the exposure conditions used in this study or they could have been counterbalanced by favorable interactions with bacteria.

According to the FCM analyses performed, we observed that exposure to GO led to an increase of chlorophyll content and to a decrease of lipid content in the diatom while opposite results were observed following rGO exposure. Although few studies monitored changes in algal physiological parameters, the results obtained in the latter case are in line with studies from the literature focusing on the effects associated to low-oxygen content GBMs exposure. Indeed, a significant reduction of chlorophyll level and an under-expression of genes associated to chlorophyll biosynthesis resulted from an exposure to $\mathrm{rGO}$ or few layer graphene in the algae Scenedesmus obliquus or N. palea, respectively (Du et al., 2016; Garacci et al., 2019). In addition, exposure to graphene nanosheets was shown to favor lipid accumulation in Chlorella pyrenoidosa (Khanra et al., 2018). However, in the case of GO exposure, our results are contradictory with the single-species-based literature that usually reports a decrease of chlorophyll pigments (Tang et al., 2015; Hu et al., 2016; Hazeem et al., 2017;
Malina et al., 2019). Nitzschia palea is a mixotrophic diatom able to grow using autotrophic metabolism (e.g., photosynthesis) using an inorganic carbon source $\left(\mathrm{CO}_{2}\right)$ and/or through a heterotrophic metabolism using organic carbon sources (Villanova et al., 2017). It was reported that mixotrophic algae accumulated chlorophyll when cultured in autotrophy, while this content decreased and lipids were accumulated by the algae under heterotrophic conditions (Cheirsilp and Torpee, 2012; da Silva Ferreira and Sant'Anna, 2017). Thus, our observations suggest that in N. palea, when it is associated to a bacterial consortium, autotrophic and heterotrophic metabolism were differentially balanced under GO or rGO exposure. In any case, these changes of the energy acquisition pathways in the diatom did not alter growth performance following $144 \mathrm{~h}$ of exposure to GBMs.

\section{Consequences of the GBMs Exposure on the Bacterial Compartment}

The effects of GBMs toward bacteria have been mainly investigated through the exposure of single bacterial strains. The effects toward bacterial communities were studied in soil (Du et al., 2015; Xiong et al., 2018; Forstner et al., 2019) or in activated sludge (Ahmed and Rodrigues, 2013; Guo et al., 2018; Yujie et al., 2020) but data remain scarce in aquatic ecosystems (Evariste et al., 2020). Given the important bacterial growth inhibition and the relatively weak consequences on microbial composition noticed after $48 \mathrm{~h}$ of exposure to GO, we can suggest that the effects of this nanomaterial could be associated to a mechanism that impacts in a similar manner most bacterial species found in this biofilm. Previous studies suggested that the membrane composition, especially in gram-negative bacteria, as well as bacterial shape could constitute a criteria of resistance to GBMs (Kang et al., 2009; Akhavan and Ghaderi, 2010; Pulingam et al., 2019; Sengupta et al., 2019). Despite that the four OTUs benefiting from exposure to high GO concentrations are Gram-negative bacteria, it is more likely that their metabolic capacities are involved in the greater tolerance to GO. Indeed, it was recently reported that bacteria from the genus Acidovorax sp. were tolerant to GO concentrations up to $95 \mathrm{mg} \cdot \mathrm{L}^{-1}$ in granulated sludge treating wastewater (Kedves et al., 2020). This genus is also well-known to be able to degrade organic matter in wastewater treatment plants (Schulze et al., 1999) as well as aromatical compounds like phenanthrene (Singleton et al., 2018) or biphenyl (Ohtsubo et al., 2012). Similarly, Silanimonas spp. are categoricized as benzene-degrading species (Mosmeri et al., 2019). Thus, we can hypothesize that these graphenetolerant bacteria benefited from the presence of GBMs in the media (i) by outcompeting other less tolerant species and (ii) because they could be able to degrade or modify the GO structure.

According to the literature, bactericidal activities of GO and rGO toward planktonic bacteria indicated generally stronger bactericidal effects of GO compared to rGO as observed in our study (Han et al., 2019). However, results concerning antibacterial effects toward bacterial biofilms are more contradictory. Indeed, strong bactericidal effects of GO were previously observed like in our study (Mejías Carpio et al., 2012; Yadav et al., 2017; Giulio et al., 2018; Pandit et al., 2018; Song et al., 2018) while others indicated that GO enhanced biofilm formation and that 
rGO exerted strong inhibitory effects (Ruiz et al., 2011; Guo et al., 2017). The interstudy discrepancies may be associated to several causes influencing the biological responses. Among the previously cited studies, when available, the characterization data indicate a wide variability within the range of oxygen content of the tested GO (from 27.8 to over 36 atomic \%), with different distribution of the types of oxygen-containing functions. In addition, depending on the method applied, the reduction of these materials lead to the production of a wide variety of rGO. This underline the need to provide detailed characterization data and the use of a classification framework to facilitate interstudy comparisons (Wick et al., 2014). Among other possible causes, it was indicated that the effects of GBMs may vary depending on the medium composition and/or on the biofilm maturity (Hui et al., 2014; Guo et al., 2017; Fallatah et al., 2019). The results obtained in our study are in line with the latter assumption as the $\mathrm{IC}_{50}$ values increased between $\mathrm{T}_{48 \mathrm{~h}}$ and $\mathrm{T}_{144 \mathrm{~h}}$, indicating that the effects of GO on bacterial growth were mitigated over time with biofilm maturation. This suggests that bacterial growth was delayed by GO exposure and that bacterial communities were recovering. However, after $144 \mathrm{~h}$ of exposure, the presence of GBMs in the media resulted in bacterial communities with diverging community structure trajectories compared to the control group. Further research would be needed to determine if bacterial communities are able to fully recover and to assess the time duration necessary for full recovery.

In addition to the effects on bacterial growth and diversity, exposure to GBMs was shown to influence microbial activities and could potentially lead to disturbances of carbon or nitrogen cycles (Zhou et al., 2019; Yilihamu et al., 2020). For example, previous studies indicated that exposure to GO or rGO could enhance the anaerobic ammonium oxidation activity that is involved in nitrogen removal in ecosystems (Wang et al., 2013; Yin et al., 2015; Tomaszewski et al., 2019). Extracellular enymatic activities involved in carbon cycling were also shown to be lowered by short term exposure to GO (Chung et al., 2015). The results obtained in our study using Biolog Ecoplates suggested that the effects of GBMs exposure on the community level physiological profiles were transitory. Indeed, the activity levels of the microbial communities were similar to the control group in the different tested conditions after $144 \mathrm{~h}$ of exposure. However, this method does not allow to determine if the increased activity is associated to an increase of intra- or extracellular metabolism. The recovery of carbon-related metabolic activities despite the changes occuring in microbial community composition could be explained by functional redundancy between the species composing the biofilm. Further experiment using other omics tools would be needed to examine the metabolic pathways that are influenced by GBMs exposure and to determine if the metabolism of compounds involved in algae-bacteria mutualistic interactions are modified (Cooper and Smith, 2015).

\section{Consequences of the Diatom-Bacteria Interactions on the Response to GBMs Exposure}

In the case of mixed-species biofilms containing phototropic microorganisms like diatoms as in our study case, the EPS produced can be used by heterotrophic bacteria as carbon and energy sources (Mühlenbruch et al., 2018). In return, bacteria may benefit diatoms by providing sources of nutrients such as vitamins or nitrogen but are also able to reduce algal oxidative stress through the production of enzymes such as catalase (Hünken et al., 2008; Amin et al., 2012; Natrah et al., 2014). Diatom-associated microbiota from environmental samples was described to mainly belong to the phylum Proteobacteria and Bacteroidota (ex phylum Bacteroidetes) that are involved in EPS degradations (Schäfer et al., 2002; Amin et al., 2012; Bohórquez et al., 2017). Thus, the composition of the bacterial compartment in the biofilm of our study is consistent with the data from the literature. The heterotrophic bacteria remineralize the organic matter produced by the diatom, ensuring an efficient nutrient cycling (Christie-Oleza et al., 2017). The functioning of biofilms relies on this mutual benefit between the algae and the bacterial consortium. In the present study, diatom and bacteria growth were not correlated across our experimental conditions, demonstrating an interplay between multiple/complex interactions and GBMs direct effects.

It has been previously shown that the exposure to carbonbased nanomaterials such as carbon nanotubes and FLG increased the EPS excretion by N. palea (Verneuil et al., 2015; Garacci et al., 2017). This mechanism was suggested to constitute a strategy allowing toxicity mitigation for the algae. However, this could have several consequences for the bacterial compartment. Indeed, the embedment of GBMs into the biofilm EPS could increase contacts with bacteria and favor membrane impairments (Dizaj et al., 2015), which could explain the strong bacterial growth inhibition that we observed in presence of GO. The differential effects observed between GO and rGO on bacterial growth might be associated to the oxidation level of the materials. Indeed, the GBMs were shown to be able to interact with natural organic matter including polysaccharydes (Chowdhury et al., 2014). As these interactions depend on the nature of oxygen-containg functional groups (Saya et al., 2021), the interaction dynamics between EPS and GO or rGO could be different, influencing the contact with bacterial cells embeded in EPS. In addition to the increase in EPS excretion, the composition and the quality of the EPS produced by the diatoms could be modified by the presence of GBMs. This was previously observed after exposure of bacteria or algae to metallic nanoparticles (Hou et al., 2015, 2017; You et al., 2015; Chen et al., 2019). Moreover, it was suggested that the energy balance between growth and EPS production could be modified following exposure to nanoparticles that is likely to occur in the case of the growth stimulation observed in our study (Taylor et al., 2016). As it was indicated that the EPS composition could affect the bacterial communities in biofilms (Haynes et al., 2007; Bohórquez et al., 2017), we can hypothesize that the changes observed in the bacterial communities could be associated to indirect effects associated to modifications of the EPS quantity and quality.

As discussed in paragraph "Consequences of the GBMs Exposure on the Algal Compartment," the growth stimulation observed in the diatom is more likely to be due to indirect effects. We can hypothesize that the overproduction of EPS associated to the 
presence of GBMs might benefit in fine to the diatoms through the increase of metabolite quantities produced by bacterial activity. In addition, the results obtained from the community level physiological profiles indicated an activation of heterotrophic metabolism of the biofilm following short term exposure to GO. This metabolic increase allowed to compensate the loss of activity that can be expected due to the bacterial growth inhibition measured in presence of GO. Indeed, considering the AWCD values for the whole biofilm (data not shown) instead of AWCD per bacterial cell as previously presented, the overall carbonrelated metabolic activities are maintained at the level of the control group until $1 \mathrm{mg} . \mathrm{L}^{-1}$ and a slight decrease is noticed at $10 \mathrm{mg} . \mathrm{L}^{-1}$ of GO. This should allow to maintain a baseline carbon and nutrient cycling between the algae and the bacteria.

\section{CONCLUSION}

In this study, we observed that the biological responses of mixed microbial communities facing exposure to GBMs were complex and contradictory to the results of single-species experiments found in the litterature. Here and according to the obtained data, we suggest that the biofilm responses were mainly associated to indirect effects initiated by the overproduction of EPS by the diatom. This potentially increased the amount of carbon available for bacterial metabolism and further benefit to the diatom. However, the oxidized form of graphene was shown to strongly impact bacterial biomass. The activities of carbon sources utilization were maintained in most conditions except at $10 \mathrm{mg} . \mathrm{L}^{-1}$ of GO that is unlikely to occur under a scenario of chronic release into the environment. However, changes associated to the diatom physiology and changes in bacterial community composition might lead to modifications of the biofilm biochemical properties and potentially affect higher trophic level organisms feeding on it. Thus, future research on the environmental risk associated to GBMs should increase environmental relevance of the bioassays.

\section{REFERENCES}

Ahmed, F., and Rodrigues, D. F. (2013). Investigation of acute effects of graphene oxide on wastewater microbial community: a case study. J. Hazard. Mater. 256-257, 33-39. doi: 10.1016/j.jhazmat.2013.03.064

Akhavan, O., and Ghaderi, E. (2010). Toxicity of graphene and graphene oxide nanowalls against bacteria. ACS Nano 4, 5731-5736. doi: 10.1021/nn101390x

Amin, S. A., Parker, M. S., and Armbrust, E. V. (2012). Interactions between diatoms and bacteria. Microbiol. Mol. Biol. Rev. 76, 667-684. doi: 10.1128/ MMBR.00007-12

Avant, B., Bouchard, D., Chang, X., Hsieh, H.-S., Acrey, B., Han, Y., et al. (2019). Environmental fate of multiwalled carbon nanotubes and graphene oxide across different aquatic ecosystems. NanoImpact 13, 1-12. doi: 10.1016/j. impact.2018.11.001

Bohórquez, J., McGenity, T. J., Papaspyrou, S., García-Robledo, E., Corzo, A., and Underwood, G. J. C. (2017). Different types of diatom-derived extracellular polymeric substances drive changes in heterotrophic bacterial communities from intertidal sediments. Front. Microbiol. 8:245. doi: 10.3389/ fmicb.2017.00245

Cacaci, M., Martini, C., Guarino, C., Torelli, R., Bugli, F., and Sanguinetti, M. (2020). Graphene oxide coatings as tools to prevent microbial biofilm

\section{DATA AVAILABILITY STATEMENT}

The original contributions presented in the study are publicly available. These data can be found in NCBI under accession number PRJNA674395.

\section{AUTHOR CONTRIBUTIONS}

LE: writing original draft - investigation - formal analysis. PB: formal analysis - investigation. FM and LG: project administration - funding acquisition. JS: resources methodology. EF: formal analysis - funding acquisition review and editing. EP: supervision - review and editing. MB: writing, review and editing - methodology - supervision. All authors contributed to the article and approved the submitted version.

\section{FUNDING}

The authors thank the European Union's Horizon 2020 research and innovation programme under grant agreement no 785219.

\section{ACKNOWLEDGMENTS}

We thank the Genotoul bioinformatics platform Toulouse MidiPyrenees and Sigenae group for providing computing and storage resources through Galaxy.

\section{SUPPLEMENTARY MATERIAL}

The Supplementary Material for this article can be found online at: https://www.frontiersin.org/articles/10.3389/fmicb.2021.623853/ full\#supplementary-material formation on medical device. Adv. Exp. Med. Biol. 1282, 21-35. doi: 10.1007/5584_2019_434

Cao, G., Yan, J., Ning, X., Zhang, Q., Wu, Q., Bi, L., et al. (2021). Antibacterial and antibiofilm properties of graphene and its derivatives. Colloids Surf. B: Biointerfaces 200:111588. doi: 10.1016/j.colsurfb.2021.111588

Castro, V. L., Clemente, Z., Jonsson, C., Silva, M., Vallim, J. H., de Medeiros, A. M. Z., et al. (2018). Nanoecotoxicity assessment of graphene oxide and its relationship with humic acid: nanoecotoxicity of graphene oxide and humic acid. Environ. Toxicol. Chem. 37, 1998-2012. doi: 10.1002/etc.4145

Cheirsilp, B., and Torpee, S. (2012). Enhanced growth and lipid production of microalgae under mixotrophic culture condition: effect of light intensity, glucose concentration and fed-batch cultivation. Bioresour. Technol. 110, 510-516. doi: 10.1016/j.biortech.2012.01.125

Chen, F., Xiao, Z., Yue, L., Wang, J., Feng, Y., Zhu, X., et al. (2019). Algae response to engineered nanoparticles: current understanding, mechanisms and implications. Environ. Sci. Nano 6, 1026-1042. doi: 10.1039/C8EN01368C

Chowdhury, I., Duch, M. C., Mansukhani, N. D., Hersam, M. C., and Bouchard, D. (2014). Interactions of graphene oxide nanomaterials with natural organic matter and metal oxide surfaces. Environ. Sci. Technol. 48, 9382-9390. doi: 10.1021/es5020828

Christie-Oleza, J. A., Sousoni, D., Lloyd, M., Armengaud, J., and Scanlan, D. J. (2017). Nutrient recycling facilitates long-term stability of marine microbial 
phototroph-heterotroph interactions. Nat. Microbiol. 2, 1-10. doi: 10.1038/ nmicrobiol.2017.100

Chung, H., Kim, M. J., Ko, K., Kim, J. H., Kwon, H., Hong, I., et al. (2015). Effects of graphene oxides on soil enzyme activity and microbial biomass. Sci. Total Environ. 514, 307-313. doi: 10.1016/j.scitotenv.2015.01.077

Clemente, Z., Silva, G. H., de Souza Nunes, M. C., Martinez, D. S. T., Maurer-Morelli, C. V., Thomaz, A. A., et al. (2019). Exploring the mechanisms of graphene oxide behavioral and morphological changes in zebrafish. Environ. Sci. Pollut. Res. 26, 30508-30523. doi: 10.1007/s11356-019-05870-z

Cooper, M. B., and Smith, A. G. (2015). Exploring mutualistic interactions between microalgae and bacteria in the omics age. Curr. Opin. Plant Biol. 26, 147-153. doi: 10.1016/j.pbi.2015.07.003

Dasari Shareena, T. P., McShan, D., Dasmahapatra, A. K., and Tchounwou, P. B. (2018). A review on graphene-based nanomaterials in biomedical applications and risks in environment and health. Nano-Micro Lett. 10:53. doi: 10.1007/ s40820-018-0206-4

da Silva Ferreira, V., and Sant'Anna, C. (2017). Impact of culture conditions on the chlorophyll content of microalgae for biotechnological applications. World J. Microbiol. Biotechnol. 33:20. doi: 10.1007/s11274-016-2181-6

Dizaj, S. M., Mennati, A., Jafari, S., Khezri, K., and Adibkia, K. (2015). Antimicrobial activity of carbon-based nanoparticles. Adv. Pharm. Bull. 5, 19-23. doi: 10.5681/apb.2015.003

Du, J., Hu, X., and Zhou, Q. (2015). Graphene oxide regulates the bacterial community and exhibits property changes in soil. RSC Adv. 5, 27009-27017. doi: 10.1039/C5RA01045D

Du, S., Zhang, P., Zhang, R., Lu, Q., Liu, L., Bao, X., et al. (2016). Reduced graphene oxide induces cytotoxicity and inhibits photosynthetic performance of the green alga Scenedesmus obliquus. Chemosphere 164, 499-507. doi: 10.1016/j.chemosphere.2016.08.138

Escudié, F., Auer, L., Bernard, M., Mariadassou, M., Cauquil, L., Vidal, K., et al. (2018). FROGS: find, rapidly, OTUs with galaxy solution. Bioinformatics 34, 1287-1294. doi: 10.1093/bioinformatics/btx791

Evariste, L., Lagier, L., Gonzalez, P., Mottier, A., Mouchet, F., Cadarsi, S., et al. (2019). Thermal reduction of graphene oxide mitigates its in vivo genotoxicity toward Xenopus laevis tadpoles. Nano 9:584. doi: 10.3390/nano9040584

Evariste, L., Mottier, A., Lagier, L., Cadarsi, S., Barret, M., Sarrieu, C., et al. (2020). Assessment of graphene oxide ecotoxicity at several trophic levels using aquatic microcosms. Carbon 156, 261-271. doi: 10.1016/j. carbon.2019.09.051

Fadeel, B., Bussy, C., Merino, S., Vázquez, E., Flahaut, E., Mouchet, F., et al. (2018). Safety assessment of graphene-based materials: focus on human health and the environment. ACS Nano 12, 10582-10620. doi: 10.1021/ acsnano. 8 b 04758

Fallatah, H., Elhaneid, M., Ali-Boucetta, H., Overton, T. W., El Kadri, H., and Gkatzionis, K. (2019). Antibacterial effect of graphene oxide (GO) nanoparticles against pseudomonas putida biofilm of variable age. Environ. Sci. Pollut. Res. 26, 25057-25070. doi: 10.1007/s11356-019-05688-9

Flemming, H.-C., Wingender, J., Szewzyk, U., Steinberg, P., Rice, S. A., and Kjelleberg, S. (2016). Biofilms: an emergent form of bacterial life. Nat. Rev. Microbiol. 14, 563-575. doi: 10.1038/nrmicro.2016.94

Forstner, C., Orton, T. G., Skarshewski, A., Wang, P., Kopittke, P. M., and Dennis, P. G. (2019). Effects of graphene oxide and graphite on soil bacterial and fungal diversity. bioRxiv 530485. doi: 10.1101/530485

Garacci, M., Barret, M., Folgoas, C., Flahaut, E., Chimowa, G., Bertucci, A., et al. (2019). Transcriptomic response of the benthic freshwater diatom Nitzschia palea exposed to few layer graphene. Environ. Sci. Nano 6, 1363-1381. doi: 10.1039/C8EN00987B

Garacci, M., Barret, M., Mouchet, F., Sarrieu, C., Lonchambon, P., Flahaut, E., et al. (2017). Few layer graphene sticking by biofilm of freshwater diatom Nitzschia palea as a mitigation to its ecotoxicity. Carbon 113, 139-150. doi: 10.1016/j.carbon.2016.11.033

Giulio, M. D., Zappacosta, R., Lodovico, S. D., Campli, E. D., Siani, G., Fontana, A., et al. (2018). Antimicrobial and antibiofilm efficacy of graphene oxide against chronic wound microorganisms. Antimicrob. Agents Chemother. 62, e00547-e00518. doi: 10.1128/AAC.00547-18

González, A. G., Mombo, S., Leflaive, J., Lamy, A., Pokrovsky, O. S., and Rols, J.-L. (2015). Silver nanoparticles impact phototrophic biofilm communities to a considerably higher degree than ionic silver. Environ. Sci. Pollut. Res. 22, 8412-8424. doi: 10.1007/s11356-014-3978-1
Goodwin, D. G., Adeleye, A. S., Sung, L., Ho, K. T., Burgess, R. M., and Petersen, E. J. (2018). Detection and quantification of Graphene-family nanomaterials in the environment. Environ. Sci. Technol. 52, 4491-4513. doi: $10.1021 /$ acs.est.7b04938

Guo, C., Wang, Y., Luo, Y., Chen, X., Lin, Y., and Liu, X. (2018). Effect of graphene oxide on the bioactivities of nitrifying and denitrifying bacteria in aerobic granular sludge. Ecotoxicol. Environ. Saf. 156, 287-293. doi: 10.1016/j.ecoenv.2018.03.036

Guo, Z., Xie, C., Zhang, P., Zhang, J., Wang, G., He, X., et al. (2017). Toxicity and transformation of graphene oxide and reduced graphene oxide in bacteria biofilm. Sci. Total Environ. 580, 1300-1308. doi: 10.1016/j.scitotenv.2016.12.093

Han, W., Wu, Z., Li, Y., and Wang, Y. (2019). Graphene family nanomaterials (GFNs) - promising materials for antimicrobial coating and film: a review. Chem. Eng. J. 358, 1022-1037. doi: 10.1016/j.cej.2018.10.106

Haynes, K., Hofmann, T. A., Smith, C. J., Ball, A. S., Underwood, G. J. C., and Osborn, A. M. (2007). Diatom-derived carbohydrates as factors affecting bacterial community composition in estuarine sediments. Appl. Environ. Microbiol. 73, 6112-6124. doi: 10.1128/AEM.00551-07

Hazeem, L. J., Bououdina, M., Dewailly, E., Slomianny, C., Barras, A., Coffinier, Y., et al. (2017). Toxicity effect of graphene oxide on growth and photosynthetic pigment of the marine alga Picochlorum sp. during different growth stages. Environ. Sci. Pollut. Res. Int. 24, 4144-4152. doi: 10.1007/s11356-016-8174-z

Hou, J., Miao, L., Wang, C., Wang, P., Ao, Y., and Lv, B. (2015). Effect of $\mathrm{CuO}$ nanoparticles on the production and composition of extracellular polymeric substances and physicochemical stability of activated sludge flocs. Bioresour. Technol. 176, 65-70. doi: 10.1016/j.biortech.2014.11.020

Hou, J., Yang, Y., Wang, P., Wang, C., Miao, L., Wang, X., et al. (2017). Effects of $\mathrm{CeO}_{2}, \mathrm{CuO}$, and $\mathrm{ZnO}$ nanoparticles on physiological features of Microcystis aeruginosa and the production and composition of extracellular polymeric substances. Environ. Sci. Pollut. Res. 24, 226-235. doi: 10.1007/s11356-016-7387-5

Hu, X., Gao, Y., and Fang, Z. (2016). Integrating metabolic analysis with biological endpoints provides insight into nanotoxicological mechanisms of graphene oxide: from effect onset to cessation. Carbon 109, 65-73. doi: 10.1016/j.carbon.2016.07.068

Hui, L., Piao, J.-G., Auletta, J., Hu, K., Zhu, Y., Meyer, T., et al. (2014). Availability of the basal planes of graphene oxide determines whether it is antibacterial. ACS Appl. Mater. Interfaces 6, 13183-13190. doi: 10.1021/am503070z

Hummers, W. S. Jr., and Offeman, R. E. (1958). Preparation of graphitic oxide. J. Am. Chem. Soc. 80, 1339-1339. doi: 10.1021/ja01539a017

Hünken, M., Harder, J., and Kirst, G. O. (2008). Epiphytic bacteria on the Antarctic ice diatom Amphiprora kufferathii Manguin cleave hydrogen peroxide produced during algal photosynthesis. Plant Biol. (Stuttg.) 10, 519-526. doi: 10.1111/j.1438-8677.2008.00040.x

Ikuma, K., Decho, A. W., and Lau, B. L. T. (2015). When nanoparticles meet biofilms-interactions guiding the environmental fate and accumulation of nanoparticles. Front. Microbiol. 6:591. doi: 10.3389/fmicb.2015.00591

Jastrzębska, A. M., and Olszyna, A. R. (2015). The ecotoxicity of graphene family materials: current status, knowledge gaps and future needs. J. Nanopart. Res. 17:40. doi: 10.1007/s11051-014-2817-0

Ji, H., Sun, H., and Qu, X. (2016). Antibacterial applications of graphene-based nanomaterials: recent achievements and challenges. Adv. Drug Deliv. Rev. 105, 176-189. doi: 10.1016/j.addr.2016.04.009

Kang, S., Mauter, M. S., and Elimelech, M. (2009). Microbial cytotoxicity of carbon-based nanomaterials: implications for river water and wastewater effluent. Environ. Sci. Technol. 43, 2648-2653. doi: 10.1021/es8031506

Kedves, A., Sánta, L., Balázs, M., Kesserü, P., Kiss, I., Rónavári, A., et al. (2020). Chronic responses of aerobic granules to the presence of graphene oxide in sequencing batch reactors. J. Hazard. Mater. 389:121905. doi: 10.1016/j.jhazmat.2019.121905

Khanra, A., Sangam, S., Shakeel, A., Suhag, D., Mistry, S., Rai, M. P., et al. (2018). Sustainable growth and lipid production from Chlorella pyrenoidosa using $\mathrm{N}$-doped carbon nanosheets: unravelling the role of graphitic nitrogen. ACS Sustain. Chem. Eng. 6, 774-780. doi: 10.1021/acssuschemeng.7b03103

Kumar, P., Huo, P., Zhang, R., and Liu, B. (2019). Antibacterial properties of graphene-based nanomaterials. Nano 9:737. doi: 10.3390/nano9050737

Lavin-Lopez, M. P., Paton-Carrero, A., Sanchez-Silva, L., Valverde, J. L., and Romero, A. (2017). Influence of the reduction strategy in the synthesis of reduced graphene oxide. Adv. Powder Technol. 28, 3195-3203. doi: 10.1016/j. apt.2017.09.032 
Lawrence, J. R., Waiser, M. J., Swerhone, G. D. W., Roy, J., Tumber, V., Paule, A., et al. (2016). Effects of fullerene (C60), multi-wall carbon nanotubes (MWCNT), single wall carbon nanotubes (SWCNT) and hydroxyl and carboxyl modified single wall carbon nanotubes on riverine microbial communities. Environ. Sci. Pollut. Res. 23, 10090-10102. doi: 10.1007/s11356-016-6244-x

Lin, L., Peng, H., and Liu, Z. (2019). Synthesis challenges for graphene industry. Nat. Mater. 18, 520-524. doi: 10.1038/s41563-019-0341-4

Liu, Y., Shi, L., Su, L., van der Mei, H. C., Jutte, P. C., Ren, Y., et al. (2019). Nanotechnology-based antimicrobials and delivery systems for biofilm-infection control. Chem. Soc. Rev. 48, 428-446. doi: 10.1039/C7CS00807D

Lobato, B., Merino, C., Barranco, V., and Centeno, T. A. (2016). Large-scale conversion of helical-ribbon carbon nanofibers to a variety of graphenerelated materials. RSC Adv. 6, 57514-57520. doi: 10.1039/C6RA08865A

Love, M. I., Huber, W., and Anders, S. (2014). Moderated estimation of fold change and dispersion for RNA-seq data with DESeq2. Genome Biol. 15:550. doi: 10.1186/s13059-014-0550-8

Lv, X., Yang, Y., Tao, Y., Jiang, Y., Chen, B., Zhu, X., et al. (2018). A mechanism study on toxicity of graphene oxide to Daphnia magna: direct link between bioaccumulation and oxidative stress. Environ. Pollut. 234, 953-959. doi: 10.1016/j.envpol.2017.12.034

Mahé, F., Rognes, T., Quince, C., de Vargas, C., and Dunthorn, M. (2014). Swarm: robust and fast clustering method for amplicon-based studies. PeerJ 2:e593. doi: 10.7717/peerj.593

Malina, T., Maršálková, E., Holá, K., Tuček, J., Scheibe, M., Zbořil, R., et al. (2019). Toxicity of graphene oxide against algae and cyanobacteria: nanoblademorphology-induced mechanical injury and self-protection mechanism. Carbon 155, 386-396. doi: 10.1016/j.carbon.2019.08.086

McMurdie, P. J., and Holmes, S. (2013). Phyloseq: an R package for reproducible interactive analysis and graphics of microbiome census data. PLoS One 8:e61217. doi: 10.1371/journal.pone.0061217

Mejías Carpio, I. E., Santos, C. M., Wei, X., and Rodrigues, D. F. (2012). Toxicity of a polymer-graphene oxide composite against bacterial planktonic cells, biofilms, and mammalian cells. Nanoscale 4, 4746-4756. doi: 10.1039/ c2nr30774j

Miao, L., Wang, P., Hou, J., Yao, Y., Liu, Z., and Liu, S. (2019). Low concentrations of copper oxide nanoparticles alter microbial community structure and function of sediment biofilms. Sci. Total Environ. 653, 705-713. doi: 10.1016/j. scitotenv.2018.10.354

Mohan, V. B., Lau, K., Hui, D., and Bhattacharyya, D. (2018). Graphene-based materials and their composites: a review on production, applications and product limitations. Compos. Part B Eng. 142, 200-220. doi: 10.1016/j. compositesb.2018.01.013

Montagner, A., Bosi, S., Tenori, E., Bidussi, M., Alshatwi, A. A., Tretiach, M., et al. (2016). Ecotoxicological effects of graphene-based materials. 2D Mater. 4:012001. doi: 10.1088/2053-1583/4/1/012001

Mosmeri, H., Gholami, F., Shavandi, M., Dastgheib, S. M. M., and Alaie, E. (2019). Bioremediation of benzene-contaminated groundwater by calcium peroxide $\left(\mathrm{CaO}_{2}\right)$ nanoparticles: continuous-flow and biodiversity studies. J. Hazard. Mater. 371, 183-190. doi: 10.1016/j.jhazmat.2019.02.071

Mottier, A., Mouchet, F., Pinelli, É., Gauthier, L., and Flahaut, E. (2017). Environmental impact of engineered carbon nanoparticles: from releases to effects on the aquatic biota. Curr. Opin. Biotechnol. 46, 1-6. doi: 10.1016/j. copbio.2016.11.024

Mühlenbruch, M., Grossart, H.-P., Eigemann, F., and Voss, M. (2018). Minireview: phytoplankton-derived polysaccharides in the marine environment and their interactions with heterotrophic bacteria. Environ. Microbiol. 20, 2671-2685. doi: 10.1111/1462-2920.14302

Nag, A., Mitra, A., and Mukhopadhyay, S. C. (2018). Graphene and its sensorbased applications: a review. Sensors Actuators A Phys. 270, 177-194. doi: 10.1016/j.sna.2017.12.028

Natrah, F. M. I., Bossier, P., Sorgeloos, P., Yusoff, F. M., and Defoirdt, T. (2014). Significance of microalgal-bacterial interactions for aquaculture. Rev. Aquac. 6, 48-61. doi: 10.1111/raq.12024

Nogueira, P. F. M., Nakabayashi, D., and Zucolotto, V. (2015). The effects of graphene oxide on green algae Raphidocelis subcapitata. Aquat. Toxicol. 166, 29-35. doi: 10.1016/j.aquatox.2015.07.001

Ohtsubo, Y., Maruyama, F., Mitsui, H., Nagata, Y., and Tsuda, M. (2012). Complete genome sequence of Acidovorax sp. strain KKS102, a polychlorinatedbiphenyl degrader. J. Bacteriol. 194, 6970-6971. doi: 10.1128/JB.01848-12
Oksanen, J., Blanchet, F. G., Kindt, R., Legendre, P., Minchin, P. R., O’hara, R. B., et al. (2015). Package 'vegan.' Community Ecol. Package Version 2.

Ouyang, S., Hu, X., and Zhou, Q. (2015). Envelopment-internalization synergistic effects and metabolic mechanisms of graphene oxide on single-cell Chlorella vulgaris are dependent on the nanomaterial particle size. ACS Appl. Mater. Interfaces 7, 18104-18112. doi: 10.1021/acsami.5b05328

Paerl, H. W., and Pinckney, J. L. (1996). A mini-review of microbial consortia: their roles in aquatic production and biogeochemical cycling. Microb. Ecol. 31, 225-247. doi: 10.1007/BF00171569

Paital, B., Guru, D., Mohapatra, P., Panda, B., Parida, N., Rath, S., et al. (2019). Ecotoxic impact assessment of graphene oxide on lipid peroxidation at mitochondrial level and redox modulation in fresh water fish Anabas testudineus. Chemosphere 224, 796-804. doi: 10.1016/j.chemosphere.2019.02.156

Pandit, S., Cao, Z., Mokkapati, V. R. S. S., Celauro, E., Yurgens, A., Lovmar, M., et al. (2018). Vertically aligned graphene coating is bactericidal and prevents the formation of bacterial biofilms. Adv. Mater. Interfaces 5:1701331. doi: 10.1002/admi.201701331

Perreault, F., Fonseca de Faria, A., and Elimelech, M. (2015). Environmental applications of graphene-based nanomaterials. Chem. Soc. Rev. 44, 5861-5896. doi: $10.1039 / \mathrm{C} 5 \mathrm{CS} 00021 \mathrm{~A}$

Pulingam, T., Thong, K. L., Ali, M. E., Appaturi, J. N., Dinshaw, I. J., Ong, Z. Y., et al. (2019). Graphene oxide exhibits differential mechanistic action towards gram-positive and gram-negative bacteria. Colloids Surf. B: Biointerfaces 181, 6-15. doi: 10.1016/j.colsurfb.2019.05.023

Quast, C., Pruesse, E., Yilmaz, P., Gerken, J., Schweer, T., Yarza, P., et al. (2012). The SILVA ribosomal RNA gene database project: improved data processing and web-based tools. Nucleic Acids Res. 41, D590-D596. doi: 10.1093/nar/gks1219

Rowley-Neale, S. J., Randviir, E. P., Abo Dena, A. S., and Banks, C. E. (2018). An overview of recent applications of reduced graphene oxide as a basis of electroanalytical sensing platforms. Appl. Mater. Today 10, 218-226. doi: 10.1016/j.apmt.2017.11.010

Ruiz, O. N., Fernando, K. A. S., Wang, B., Brown, N. A., Luo, P. G., McNamara, N. D., et al. (2011). Graphene oxide: a nonspecific enhancer of cellular growth. ACS Nano 5, 8100-8107. doi: 10.1021/nn202699t

Saxena, P., Sangela, V., Ranjan, S., Dutta, V., Dasgupta, N., Phulwaria, M., et al. (2020). Aquatic nanotoxicology: impact of carbon nanomaterials on algal flora. Energy Ecol. Environ. 5, 240-252. doi: 10.1007/s40974-020-00151-9

Saya, L., Gautam, D., Malik, V., Singh, W. R., and Hooda, S. (2021). Natural polysaccharide based graphene oxide nanocomposites for removal of dyes from wastewater: a review. J. Chem. Eng. Data 66, 11-37. doi: 10.1021/acs.jced.0c00743

Scala, S., and Bowler, C. (2001). Molecular insights into the novel aspects of diatom biology. Cell. Mol. Life Sci. 58, 1666-1673. doi: 10.1007/PL00000804

Schäfer, H., Abbas, B., Witte, H., and Muyzer, G. (2002). Genetic diversity of "satellite" bacteria present in cultures of marine diatoms. FEMS Microbiol. Ecol. 42, 25-35. doi: 10.1111/j.1574-6941.2002.tb00992.x

Schulze, R., Spring, S., Amann, R., Huber, I., Ludwig, W., Schleifer, K.-H., et al. (1999). Genotypic diversity of Acidovorax strains isolated from activated sludge and description of Acidovorax defluvii sp. nov. Syst. Appl. Microbiol. 22, 205-214. doi: 10.1016/S0723-2020(99)80067-8

Sengupta, I., Bhattacharya, P., Talukdar, M., Neogi, S., Pal, S. K., and Chakraborty, S. (2019). Bactericidal effect of graphene oxide and reduced graphene oxide: influence of shape of bacteria. Colloid Interface Sci. Commun. 28, 60-68. doi: 10.1016/j.colcom.2018.12.001

Singleton, D. R., Lee, J., Dickey, A. N., Stroud, A., Scholl, E. H., Wright, F. A., et al. (2018). Polyphasic characterization of four soil-derived phenanthrenedegrading Acidovorax strains and proposal of Acidovorax carolinensis sp. nov. Syst. Appl. Microbiol. 41, 460-472. doi: 10.1016/j.syapm.2018.06.001

Smith, A. T., LaChance, A. M., Zeng, S., Liu, B., and Sun, L. (2019). Synthesis, properties, and applications of graphene oxide/reduced graphene oxide and their nanocomposites. Nano Mater. Sci. 1, 31-47. doi: 10.1016/j.nanoms.2019.02.004

Song, C., Yang, C.-M., Sun, X.-F., Xia, P.-F., Qin, J., Guo, B.-B., et al. (2018). Influences of graphene oxide on biofilm formation of gram-negative and gram-positive bacteria. Environ. Sci. Pollut. Res. Int. 25, 2853-2860. doi: 10.1007/s11356-017-0616-8

Sun, T. Y., Bornhöft, N. A., Hungerbühler, K., and Nowack, B. (2016). Dynamic probabilistic modeling of environmental emissions of engineered nanomaterials. Environ. Sci. Technol. 50, 4701-4711. doi: 10.1021/acs.est.5b05828

Tang, Y., Tian, J., Li, S., Xue, C., Xue, Z., Yin, D., et al. (2015). Combined effects of graphene oxide and $c d$ on the photosynthetic capacity and survival 
of Microcystis aeruginosa. Sci. Total Environ. 532, 154-161. doi: 10.1016/j. scitotenv.2015.05.081

Tarcan, R., Todor-Boer, O., Petrovai, I., Leordean, C., Astilean, S., and Botiz, I. (2020). Reduced graphene oxide today. J. Mater. Chem. C 8, 1198-1224. doi: 10.1039/C9TC04916A

Tashan, H., Khosravi-Darani, K., Yazdian, F., Omidi, M., Sheikhpour, M., Farahani, M., et al. (2019). Antibacterial properties of graphene based nanomaterials: an emphasis on molecular mechanisms, surface engineering and size of sheets. Mini-Rev. Org. Chem. 16, 159-172. doi: 10.2174/1570193X15666180712120309

Taylor, C., Matzke, M., Kroll, A., Read, D. S., Svendsen, C., and Crossley, A. (2016). Toxic interactions of different silver forms with freshwater green algae and cyanobacteria and their effects on mechanistic endpoints and the production of extracellular polymeric substances. Environ. Sci. Nano 3, 396-408. doi: 10.1039/C5EN00183H

Thamatrakoln, K., Korenovska, O., Niheu, A. K., and Bidle, K. D. (2012). Whole-genome expression analysis reveals a role for death-related genes in stress acclimation of the diatom Thalassiosira pseudonana. Environ. Microbiol. 14, 67-81. doi: 10.1111/j.1462-2920.2011.02468.x

Tomaszewski, M., Cema, G., and Ziembińska-Buczyńska, A. (2019). Short-term effects of reduced graphene oxide on the anammox biomass activity at low temperatures. Sci. Total Environ. 646, 206-211. doi: 10.1016/j.scitotenv.2018.07.283

Verneuil, L., Silvestre, J., Randrianjatovo, I., Marcato-Romain, C.-E., Girbal-Neuhauser, E., Mouchet, F., et al. (2015). Double walled carbon nanotubes promote the overproduction of extracellular protein-like polymers in Nitzschia palea: an adhesive response for an adaptive issue. Carbon 88, 113-125. doi: 10.1016/j.carbon.2015.02.053

Villanova, V., Fortunato, A. E., Singh, D., Bo, D. D., Conte, M., Obata, T., et al. (2017). Investigating mixotrophic metabolism in the model diatom Phaeodactylum tricornutum. Philos. Trans. R. Soc. B Biol. Sci. 372:20160404. doi: $10.1098 /$ rstb.2016.0404

Wang, A., Pu, K., Dong, B., Liu, Y., Zhang, L., Zhang, Z., et al. (2013). Role of surface charge and oxidative stress in cytotoxicity and genotoxicity of graphene oxide towards human lung fibroblast cells: toxicity of graphene oxide to HLF cells. J. Appl. Toxicol. 33, 1156-1164. doi: 10.1002/jat.2877

Wang, Y., and Qian, P.-Y. (2009). Conservative fragments in bacterial $16 \mathrm{~S}$ rRNA genes and primer design for $16 \mathrm{~S}$ ribosomal DNA amplicons in metagenomic studies. PLoS One 4:e7401. doi: 10.1371/journal.pone.0007401

Weber, K. P., and Legge, R. L. (2009). One-dimensional metric for tracking bacterial community divergence using sole carbon source utilization patterns. J. Microbiol. Methods 79, 55-61. doi: 10.1016/j.mimet.2009.07.020

Wick, P., Louw-Gaume, A. E., Kucki, M., Krug, H. F., Kostarelos, K., Fadeel, B., et al. (2014). Classification framework for graphene-based materials. Angew. Chem. Int. Ed. Eng. 53, 7714-7718. doi: 10.1002/anie.201403335

Xiong, T., Yuan, X., Wang, H., Leng, L., Li, H., Wu, Z., et al. (2018). Implication of graphene oxide in Cd-contaminated soil: a case study of bacterial communities. J. Environ. Manag. 205, 99-106. doi: 10.1016/j.jenvman.2017.09.067
Yadav, N., Dubey, A., Shukla, S., Saini, C. P., Gupta, G., Priyadarshini, R., et al. (2017). Graphene oxide-coated surface: inhibition of bacterial biofilm formation due to specific surface-interface interactions. ACS Omega 2, 3070-3082. doi: 10.1021/acsomega.7b00371

Yilihamu, A., Ouyang, B., Ouyang, P., Bai, Y., Zhang, Q., Shi, M., et al. (2020). Interaction between graphene oxide and nitrogen-fixing bacterium Azotobacter chroococcum: transformation, toxicity and nitrogen fixation. Carbon 160, 5-13. doi: 10.1016/j.carbon.2020.01.014

Yin, X., Qiao, S., Yu, C., Tian, T., and Zhou, J. (2015). Effects of reduced graphene oxide on the activities of anammox biomass and key enzymes. Chem. Eng. J. 276, 106-112. doi: 10.1016/j.cej.2015.04.073

You, G., Hou, J., Xu, Y., Wang, C., Wang, P., Miao, L., et al. (2015). Effects of $\mathrm{CeO} 2$ nanoparticles on production and physicochemical characteristics of extracellular polymeric substances in biofilms in sequencing batch biofilm reactor. Bioresour. Technol. 194, 91-98. doi: 10.1016/j.biortech.2015.07.006

Yujie, S., Jian, L., Yu, J., Xu, S., Wenning, Y., Zhenghua, L., et al. (2020). Effect of graphene oxide on the ammonia removal and bacterial community in a simulated wastewater treatment process. J. Environ. Eng. 146:04020097. doi: 10.1061/(ASCE)EE.1943-7870.0001781

Zhang, X., Zhou, Q., Zou, W., and Hu, X. (2017). Molecular mechanisms of developmental toxicity induced by graphene oxide at predicted environmental concentrations. Environ. Sci. Technol. 51, 7861-7871. doi: 10.1021/acs. est.7b01922

Zhao, J., Cao, X., Wang, Z., Dai, Y., and Xing, B. (2017). Mechanistic understanding toward the toxicity of graphene-family materials to freshwater algae. Water Res. 111, 18-27. doi: 10.1016/j.watres.2016.12.037

Zhao, J., Li, Y., Cao, X., Guo, C., Xu, L., Wang, Z., et al. (2019). Humic acid mitigated toxicity of graphene-family materials to algae through reducing oxidative stress and heteroaggregation. Environ. Sci. Nano 6, 1909-1920. doi: 10.1039/C9EN00067D

Zhou, N., Zhao, Z., Wang, H., Chen, X., Wang, M., He, S., et al. (2019). The effects of graphene oxide on nitrification and $\mathrm{N}_{2} \mathrm{O}$ emission: dose and exposure time dependent. Environ. Pollut. 252, 960-966. doi: 10.1016/j. envpol.2019.06.009

Conflict of Interest: The authors declare that the research was conducted in the absence of any commercial or financial relationships that could be construed as a potential conflict of interest.

Copyright (c) 2021 Evariste, Braylé, Mouchet, Silvestre, Gauthier, Flahaut, Pinelli and Barret. This is an open-access article distributed under the terms of the Creative Commons Attribution License (CC BY). The use, distribution or reproduction in other forums is permitted, provided the original author(s) and the copyright owner(s) are credited and that the original publication in this journal is cited, in accordance with accepted academic practice. No use, distribution or reproduction is permitted which does not comply with these terms. 